\title{
Compressão do gânglio de Gasser e da raiz trige- minal com balão no tratamento da neuralgia do nervo trigêmeo: Estudo prospectivo de 40 doentes
}

\author{
Heider Lopes de Souza*, Manoel Jacobsen Texeira**, Oswaldo Inácio de Tella Jr. ${ }^{* *}$
}

Resumo da Tese apresentada à Disciplina de Neurologia e Neurocirurgia da Escola Paulista de Medicina (UNIFESP) para obtenção do título de Doutor em Medicina

\section{RESUMO}

São apresentados os resultados do tratamento cirúrgico de 40 doentes com neuralgia essencial do nervo trigêmeo submetidos à compressão do gânglio de Gasser e da raiz trigeminal com balão de Fogarty. A história natural da neuralgia do trigêmeo, os dados demográficos e as características clínicas foram semelhantes aos descritos na literatura. Foram realizadas 50 rizotomias por compressão: 30 doentes foram submetidos a uma única compressão; 9 , a duas; $e$, 1 , à compressão bilateral. O tempo de acompanhamento variou de 6 a 48 meses.

O primeiro procedimento aliviou a dor em $37(90,26 \%)$ hemifaces e, o segundo, em $9(100 \%)$. A freqüência de complicações imediatas e tardias foi insignificante. A dor recorreu em 6 (15\%) doentes durante os primeiros 48 meses de acompanhamento, em 4 durante os primeiros 24 meses, em 1 aos 36 meses, e outro, aos 42 meses. Dois (5\%) doentes não apresentaram melhora da dor após a primeira intervenção e foram submetidos à nova compressão durante as primeiras 24 horas após o primeiro procedimento, apresentando alívio da dor. Dois (5\%) outros doentes apresentaram alívio parcial da dor; um não aceitou a segunda operação e o outro foi operado seis meses após a primeira cirurgia. Foram analisados os resultados em relação ao tempo de duração da compressão, e à forma e volume do balão. O tempo de duração da primeira compressão foi de 60 segundos e, o da segunda, 120 segundos. Durante o procedimento procurou-se induzir, ao balão, a forma de pêra ou ampulheta. A hipoestesia da face foi, na maioria dos doentes, discreta; tornou-se moderada, mas não desagradável, quando a compressão durou mais de 60 segundos ou quando o balão adquiriu a forma de ampulheta. Todos os nove doentes submetidos à segunda compressão apresentaram acentuação da hipoestesia facial, ou seja, hipoestesia moderada. A satisfação dos doentes foi elevada.

Concluiu-se que a rizotomia por compressão com balão é eficaz no tratamento da dor da neuralgia do nervo trigêmeo, não acarretando anestesia corneana ou ceratite, podendo ser realizada sob anestesia geral de curta duração, não necessitando colaboração do doente durante sua execução. Ocorreu tendência de os doentes, quando a forma em ampulheta foi induzida ao balão, apresentar maior freqüência de alívio da dor, e naqueles em que a forma de pêra foi induzida, apresentar maior magnitude do déficit motor mastigatório e sensitivo da face. O período de acompanhamento foi de até 48 meses e a taxa final de recorrência, $15 \%$.

\section{PALAVRAS-CHAVE}

Neuralgia do trigêmeo. Rizotomia por compressão com balão.

\section{ABSTRACT}

Compression of Gasserian ganglion and trigeminal roots with balloon for treatment of trigeminal neuralgia: A prospective study of 40 patients

Forty patients presenting trigeminal neuralgia which underwent Gasserian ganglion and trigeminal root compression with Fogarty's balloon are presented. The natural history, the clinical presentation and the demographic aspects of the patients were similar to that described in the literature. Fifty procedures were performed; 30 patients underwent one compression; nine, two and in one patient the procedure was bilateral. The follow-up ranged from six to 48 months.

The first compression procedure was effective in $37(90,26 \%)$ hemifaces and the second procedure alleviated pain in nine (100\%) patients. There were only minor immediate and late complication rates. Recurrence of pain occurred in six (15\%) patients during the 48 months follow-up period; four during the first 24 months; one at the 36th month, and the remainder at the 42nd month. Two (5\%) patients did not present relief of pain and underwent a second procedure during the first 24

* Professor Adjunto Doutor em Medicina do Departamento de Cirurgia da Universidade Federal do Rio Grande do Norte.

**Professor Adjunto Doutor em Medicina do Departamento de Neurologia da Faculdade de Medicina da Universidade de São Paulo. Orientador.

***Professor Adjunto Doutor Livre-Docente da Disciplina de Neurologia e Neurocirurgia da Universidade Federal de São Paulo. Co-orientador. 
hours after the first one and had total pain relief. Two (5\%) other patients presented partial pain relief; one did not agree with the second procedure and the other was operated six months after the first surgery. Compression time, the balloon shape obtained during the procedure and volume injected into the balloon were analyzed. The first compression lasted 60 seconds and the second, 120 seconds. During the procedure, pear or hourglass shape of the balloon were induced. Hemifacial numbness following the procedure was mild in most patients; it was moderate but not disagreeable when the compression time was longer or when the balloon had an hourglass shape. After the second compression all patients presented intensification of the hemifacial numbness.

It is concluded that the Gasserian ganglion compression with balloon is efficient, the complication rate is low, the procedure can be performed under light general anesthesia, as the cooperation of the patient is not needed. There was a tendency to get better results in patients with an hourglass shape balloon achievement. When a pear shape balloon was achieved a motor mastigatory deficit and facial numbness were observed. The maximum follow-up period was 48 months and the recurrence rate was $15 \%$.

\section{KEYWORDS}

Trigeminal neuralgia. Balloon compression of Gasserian ganglion.

\section{Introdução}

Há evidências de que a neuralgia do trigêmeo seja tão antiga quanto o próprio homem. Entretanto, só a partir da segunda metade do século XV seus aspectos clínicos foram descritos com detalhes. Apesar do grande progresso observado nos últimos anos no campo das avaliações laboratoriais e de imagem da dor facial, muitos aspectos necessitam ser esclarecidos sobre a fisiologia e a anatomia das unidades centrais e periféricas do nervo trigêmeo, bem como sobre a fisiopatologia da dor trigeminal e, especialmente, sobre as estratégias terapêuticas destinadas a seu controle.

A história da cirurgia da neuralgia do trigêmeo demonstra quanto o uso abusivo de procedimentos muitas vezes empíricos, mutilantes e incapacitantes foram empregados para seu tratamento no passado e que métodos operatórios foram surgindo seguindo a tática de adição e subtração de variantes de técnicas preexistentes, seguindo o princípio de tentativas e erros, ou ao acaso, objetivando maior eficácia, simplicidade e segurança. A existência de diversas técnicas cirúrgicas para o controle da dor trigeminal demonstra que o procedimento ideal ainda não foi descrito. Entretanto, ainda, nenhum método operatório deve ser considerado curativo ou desprovido de complicações.

Os procedimentos cirúrgicos destinados ao tratamento da dor facial podem ser realizados percutaneamente ou a céu aberto. Podem visar à eliminação das supostas causas ou apenas ao alívio da sintomatologia. A escolha do método depende das condições clínicas dos doentes, da etiologia da dor facial, da experiência do neurocirurgião e das condições do ambiente onde o doente é tratado. Devem ser evitadas as técnicas que, interrompendo completamente as vias trigeminais, geram fenômenos secundários, incluindo a dor por desaferentação. As neurectomias e as alcoolizações dos ramos periféricos, a alcoolização do gânglio de Gasser e da raiz trigeminal e a secção da raiz sensitiva na fossa média ou posterior são pouco indicadas na atualidade. A interrupção do trato espinal, das conexões centrais e das unidades de processamento central do nervo trigêmeo ou das estruturas envolvidas no controle do comportamento psíquico, bem como a estimulação elétrica das vias trigeminais e a infusão de fármacos analgésicos nos ventrículos encefálicos, é indicada em casos especiais. A descompressão microcirúrgica da raiz trigeminal, apesar de amplamente utilizada, apresenta alto custo operacional, risco de complicações graves e, a longo prazo, elevada possibilidade de recidivas. Os procedimentos percutâneos, atualmente em uso, incluem a neurólise térmica, química e mecânica da raiz trigeminal, e se caracterizam pela simplicidade, segurança de execução e pelos bons resultados que proporcionam. Entre estes últimos procedimentos, destaca-se a compressão do gânglio de Gasser e das raízes trigeminais com balão. Entretanto, alguns aspectos dessa técnica operatória necessitam, ainda, ser padronizados, o que justifica a realização deste trabalho.

\section{Casuística e método}

Este trabalho é baseado na observação prospectiva de 40 doentes com neuralgia essencial do nervo trigêmeo tratados pela técnica de compressão do gânglio de Gasser com balão (CGGB), na Clínica Neurológica do Hospital Universitário Onofre Lopes, da Faculdade de Medicina da Universidade Federal do Rio Grande do Norte, no período de julho de 1995 a julho de 1999.

Todos os doentes que concordaram em participar da investigação, que foi aprovada pela Comissão de Ética do Hospital, assinaram o Termo de Consentimento Livre e Esclarecido e a Carta de Informação.

Foram selecionados, sucessivamente, doentes com neuralgia do trigêmeo incapacitante e resistente ao tratamento medicamentoso que não haviam sido submetidos a tratamentos operatórios prévios e que concordaram com a realização do procedimento de CGGB. Todos os doentes foram previamente orientados quanto a necessidade, riscos e vantagens do procedimento. 
Foram colhidos dados sobre demografia e sobre os históricos médicos e da neuralgia do trigêmeo, incluindo os antecedentes familiares e pessoais, os hábitos e informações sobre os diversos aparelhos e sistemas, assim como foi realizado exame físico geral e exame neurológico de todos os doentes. Hemograma, exame bioquímico do sangue (dosagem de sódio, potássio, uréia, creatinina e glicemia) e tomografia computadorizada (TC) do segmento cefálico foram realizados em todos os doentes. A ressonância mag- nética ( $\mathrm{RM}$ ) foi realizada em três doentes com idade inferior a 50 anos; o exame do líquido cerebrospinal, em um; e o estudo angiográfico do território arterial vertebrobasilar, em três doentes em que havia suspeita de ectasia e alongamento da artéria basilar ao exame de TC.

No quadro 1 são apresentados os principais dados referentes aos aspectos demográficos, dados sobre a neuralgia do trigêmeo, assim como o período de acompanhamento de cada doente.

\begin{tabular}{|c|c|c|c|c|c|c|c|c|c|}
\hline \multicolumn{10}{|c|}{$\begin{array}{l}\text { Distribuição dos doentes quanto à identificação (número de ordem, iniciais, sexo, idade), tempo de duração da } \\
\text { sintomatologia, freqüência da ocorrência dos episódios dolorosos, duração, ou não, da ocorrência de períodos de } \\
\text { remissão da dor, ramo acometido, lado da face acometido pela dor e duração do acompanhamento }\end{array}$} \\
\hline $\begin{array}{l}\text { Número de } \\
\text { ordem }\end{array}$ & Iniciais & Sexo & $\begin{array}{l}\text { Idade } \\
\text { (anos) }\end{array}$ & $\begin{array}{c}\text { Tempo de } \\
\text { dor (anos) }\end{array}$ & $\begin{array}{c}\text { Freqüência } \\
\text { da dor }\end{array}$ & $\begin{array}{c}\text { Períodos } \\
\text { de remissão }\end{array}$ & $\begin{array}{c}\text { Ramo } \\
\text { acometido }\end{array}$ & $\begin{array}{c}\text { Lado } \\
\text { acometido }\end{array}$ & $\begin{array}{l}\text { Tempo de } \\
\text { acompanhamento } \\
\text { (meses) }\end{array}$ \\
\hline 1 & MLS & Feminino & 69 & 4 & Diária & Dias & $\mathrm{V} 2 / \mathrm{V} 3$ & Direito & 6 \\
\hline 2 & $\mathrm{SF}$ & Feminino & 39 & 3 & Diária & Semanas & $\mathrm{V} 2 / \mathrm{V} 3$ & Direito & 6 \\
\hline 3 & DLS & Feminino & 53 & 5 & Diária & Dias & $\mathrm{V} 2 / \mathrm{V} 3$ & Direito & 6 \\
\hline 4 & FA & Feminino & 68 & 8 & Diária & Ausentes & $\mathrm{V} 2 / \mathrm{V} 3$ & Direito & 6 \\
\hline 5 & JLM & Feminino & 66 & 6 & Semanal & Dias & $\mathrm{V} 2 / \mathrm{V} 3$ & Esquerdo & 6 \\
\hline 6 & LAD & Masculino & 63 & 10 & Diária & Meses & V3 & Esquerdo & 6 \\
\hline 7 & MAD & Feminino & 55 & 3 & Diária & Dias & $\mathrm{V} 2 / \mathrm{V} 3$ & Esquerdo & 6 \\
\hline 8 & MBN & Feminino & 83 & 6 & Diária & Semanas & $\mathrm{V} 2 / \mathrm{V} 3$ & Direito & 6 \\
\hline 9 & ZDS & Feminino & 52 & 4 & Diária & Semanas & $\mathrm{V} 1 / \mathrm{V} 2$ & Esquerdo & 6 \\
\hline 10 & CBS & Masculino & 67 & 10 & Diária & Dias & $\mathrm{V} 2 / \mathrm{V} 3$ & Esquerdo & 7 \\
\hline 11 & MNL & Feminino & 55 & 3 & Diária & Dias & $\mathrm{V} 2 / \mathrm{V} 3$ & Direito & 7 \\
\hline 12 & JBN & Feminino & 76 & 5 & Diária & Dias & $\mathrm{V} 2 / \mathrm{V} 3$ & Direito & 7 \\
\hline 13 & $\mathrm{RBN}$ & Masculino & 76 & 7 & Diária & Meses & V3 & Esquerdo & 8 \\
\hline 14 & MJS & Masculino & 56 & 2 & Diária & Semanas & $\mathrm{V} 1 / \mathrm{V} 2 / \mathrm{V} 3$ & Esquerdo & 10 \\
\hline 15 & MJ & Masculino & 70 & 2 & Diária & Semanas & $\mathrm{V} 1 / \mathrm{V} 2$ & Direito & 12 \\
\hline 16 & $\mathrm{AD}$ & Feminino & 72 & 4 & Diária & Meses & $\mathrm{V} 2 / \mathrm{V} 3$ & Esquerdo & 12 \\
\hline 17 & AFM & Masculino & 55 & 2 & Diária & Semanas & $\mathrm{V} 2 / \mathrm{V} 3$ & Esquerdo & 12 \\
\hline 18 & FFO & Feminino & 57 & 6 & Semanal & Dias & $\mathrm{V} 2 / \mathrm{V} 3$ & Esquerdo & 18 \\
\hline 19 & TML & Masculino & 71 & 5 & Semanal & Dias & $\mathrm{V} 2 / \mathrm{V} 3$ & Esquerdo & 18 \\
\hline 20 & FES & Feminino & 72 & 4 & Semanal & Meses & $\mathrm{V} 2 / \mathrm{V} 3$ & Direito & 18 \\
\hline 21 & JFS & Feminino & 59 & 8 & Diária & Dias & $\mathrm{V} 1 / \mathrm{V} 2 / \mathrm{V} 3$ & Esquerdo & 18 \\
\hline 22 & JSS & Masculino & 67 & 10 & Diária & Semanas & $\mathrm{V} 2 / \mathrm{V} 3$ & Direito & 18 \\
\hline 23 & MNCL & Feminino & 68 & 5 & Diária & Dias & $\mathrm{V} 2 / \mathrm{V} 3$ & Direito & 18 \\
\hline 24 & MLC & Feminino & 78 & 6 & Diária & Dias & $\mathrm{V} 2 / \mathrm{V} 3$ & Direito & 24 \\
\hline 25 & JLM & Masculino & 61 & 5 & Semanal & Dias & $\mathrm{V} 2 / \mathrm{V} 3$ & Esquerdo & 24 \\
\hline 26 & RJOS & Feminino & 71 & 8 & Semanal & Dias & $\mathrm{V} 2 / \mathrm{V} 3$ & Direito & 24 \\
\hline 27 & $\mathrm{SC}$ & Feminino & 70 & 6 & Diária & Meses & $\mathrm{V} 2 / \mathrm{V} 3$ & Esquerdo & 24 \\
\hline 28 & AAS & Masculino & 67 & 5 & Diária & Dias & $\mathrm{V} 2$ & Esquerdo & 25 \\
\hline 29 & MCS & Feminino & 66 & 5 & Mensal & Dias & V3 & Direito & 26 \\
\hline 30 & NP & Masculino & 69 & 12 & Semanal & Meses & $\mathrm{V} 2 / \mathrm{V} 3$ & Direito & 28 \\
\hline 31 & AJS & Masculino & 63 & 6 & Diária & Semanas & $\mathrm{V} 2$ & Esquerdo & 30 \\
\hline $32 *$ & MDS & Feminino & 53 & 3 & Diária & Semanas & $\mathrm{V} 2 / \mathrm{V} 3$ & Direito & 30 \\
\hline 33 & MBN & Feminino & 82 & 7 & Semanal & Dias & $\mathrm{V} 1 / \mathrm{V} 2 / \mathrm{V} 3$ & Direito & 30 \\
\hline 34 & LAC & Masculino & 65 & 10 & Diária & Meses & $\mathrm{V} 2 / \mathrm{V} 3$ & Esquerdo & 30 \\
\hline 35 & AAS & Feminino & 69 & 8 & Diária & Dias & $\mathrm{V} 2 / \mathrm{V} 3$ & Esquerdo & 42 \\
\hline 36 & $\mathrm{AR}$ & Feminino & 68 & 8 & Diária & Dias & $\mathrm{V} 2 / \mathrm{V} 3$ & Esquerdo & 42 \\
\hline 37 & JLC & Feminino & 61 & 4 & Diária & Dias & $\mathrm{V} 2 / \mathrm{V} 3$ & Direito & 48 \\
\hline 38 & ETL & Masculino & 72 & 6 & Diária & Meses & $\mathrm{V} 1 / \mathrm{V} 2 / \mathrm{V} 3$ & Direito & 48 \\
\hline 39 & TML & Feminino & 68 & 5 & Diária & Dias & $\mathrm{V} 2 / \mathrm{V} 3$ & Esquerdo & 48 \\
\hline 40 & MLAC & Feminino & 71 & 6 & Diária & Dias & $\mathrm{V} 2 / \mathrm{V} 3$ & Direito & 48 \\
\hline
\end{tabular}

*Neuralgia do trigêmeo bilateral; V1 - ramo oftálmico; V2 - ramo maxilar; V3 - ramo mandibular 


\section{Técnica operatória}

Em ambiente de centro cirúrgico e após jejum de, pelo menos, oito horas, os doentes foram monitorizados com cardioscopia e oximetria de pulso. Foi instalado acesso venoso para administração de fluidos, fármacos anestésicos e, quando necessário, de drogas vasoativas. Com o doente em posição supina, estando a cabeça em posição neutra e com o eixo occipitofrontal a $90^{\circ} \mathrm{em}$ relação ao plano horizontal, assepsia da hemiface ipsilateral foi realizada com sabão líquido e polivinilpirrolidona. A seguir, os doentes foram mantidos sob anestesia geral, com propofol e fentanila, combinada com a infiltração do tegumento da face com lidocaína a $2 \%$, em um ponto localizado a $2 \mathrm{~cm}$ lateral $1 \mathrm{~cm}$ superiormente ao canto da boca. A punção do forame oval foi realizada segundo a técnica descrita por Hartel ${ }^{48}$.

Ventilação foi realizada com máscara; eventualmente foi necessária a intubação endotraqueal, quando ocorreu depressão respiratória. Dose de $0,1 \mathrm{mg}$ de atropina por via intravenosa foi administrada quando ocorreu redução de mais de $20 \%$ da freqüência cardíaca basal, durante a punção do forame oval ou durante a compressão pelo balão (Figura 1).

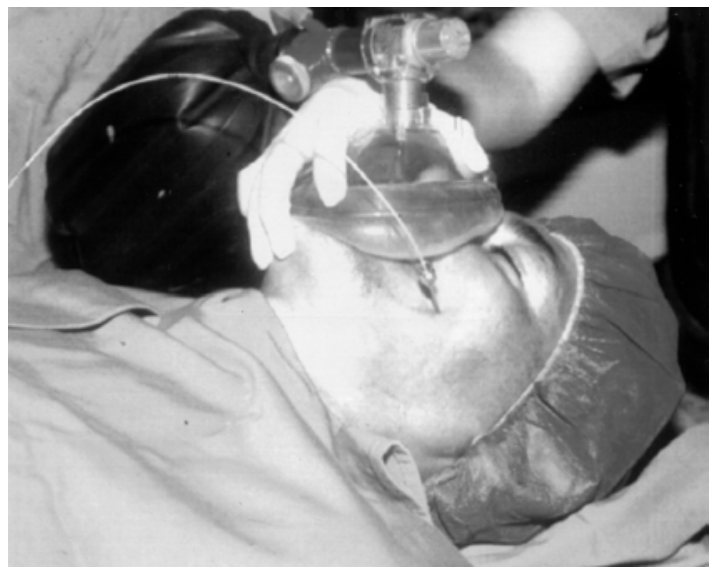

Figura 1 - Reprodução fotográfica da execução do procedimento de compressão do gânglio de Gasser com balão, observando-se a possibilidade de ventilação sob máscara e o posicionamento da agulha de punção e do cateter de Fogarty.

Antecedendo o procedimento propriamente dito, foi verificada a permeabilidade da agulha e realizada insuflação do balão com contraste iodado para determinação de sua integridade. Com guia metálico introduzido no interior do cateter para torná-lo radiopaco e sob controle radioscópico, na incidência de perfil, uma agulha $14 \mathrm{G}$ de biópsia hepática - tipo Sylverman - ou de punção epidural $15 \mathrm{G}$ (Pierces ${ }^{\circledR}$, Medtronics Inc., Minneapolis, EUA) foi dirigida para o ângulo formado pela intersecção do plano que passa pelo dorso da sela turca com a pirâmide petrosa até penetrar no forame oval. Após a punção do forame oval, retirou-se o mandril da agulha, mantendo-se, manualmente, sua posição no local de punção. A seguir, um cateter de Fogarty $4 \mathrm{~F}$ (American Edwards Laboratory, Inc., EUA) foi introduzido através da luz da agulha, no interior do cavum de Meckel e deslocado na distância de $10 \mathrm{~mm}$ até ter sua extremidade visualizada tocando o plano paralelo ao dorso da sela turca. O balão foi, então, lentamente inflado com 0,7 a $1 \mathrm{ml}$ de iopamidol (Iopamiron $125^{\circledR}$ ) e assim mantido, durante 60 segundos, quando da realização do primeiro procedimento, e por 120 segundos, quando da necessidade de procedimentos complementares. A seguir, procedeu-se o esvaziamento do balão e remoção conjunta do cateter e agulha.

A forma do balão (classificada como oval, em pêra ou ampulheta), a freqüência cardíaca, a pressão arterial e a ocorrência de hiperemia conjuntival foram anotadas (Figura 2).

O controle da sintomatologia foi classificado como alívio, melhora ou como falha do procedimento. Alívio significou desaparecimento da dor. Melhora significou persistência de zonas de gatilho e dor menos intensa. Falha do tratamento significou ausência de melhora ou impossibilidade de punção do forame oval.

A avaliação da sensibilidade tátil da face foi realizada com algodão e a da sensibilidade dolorosa com alfinete. Foi também questionado aos doentes a ocorrência ou não de sensação de dormência, classificada analogicamente, segundo relato verbal, como discreta, moderada ou intensa. O déficit motor foi avaliado considerando-se a ocorrência de desvio da mandíbula para o lado acometido pela dor e a descrição, pelos doentes, de comprometimento da mastigação; foi considerado moderado o déficit que impossibilitou a mastigação e discreto quando isso não ocorreu.

Todos os doentes foram tratados ambulatorialmente ou permaneceram internados por período de tempo inferior a 24 horas.

Para a anotação dos resultados foi utilizado um protocolo, em que foram anotados dados referentes às características dos doentes e da síndrome neurálgica, os parâmetros do procedimento cirúrgico (duração da compressão, volume de contraste injetado, forma do balão, ocorrência ou não de bradicardia), a natureza da melhora ou não da dor, o grau das anormalidades sensitivas induzidas ou não, a magnitude dos déficits induzidos ou não na musculatura mastigatória, a ocorrência ou não de lesão de outros nervos cranianos, o período de acompanhamento e a ocorrência de recorrência da dor.

Com o intuito de caracterizar a amostra, foi realizada análise descritiva de todas as variáveis. Para a análise das variáveis qualitativas, os dados foram resumidos em freqüências simples e relativas (percentuais). As informações referentes às variáveis quantitativas foram expressas na forma de médias, medianas, desvios padrões e valores mínimos e máximos. 
A

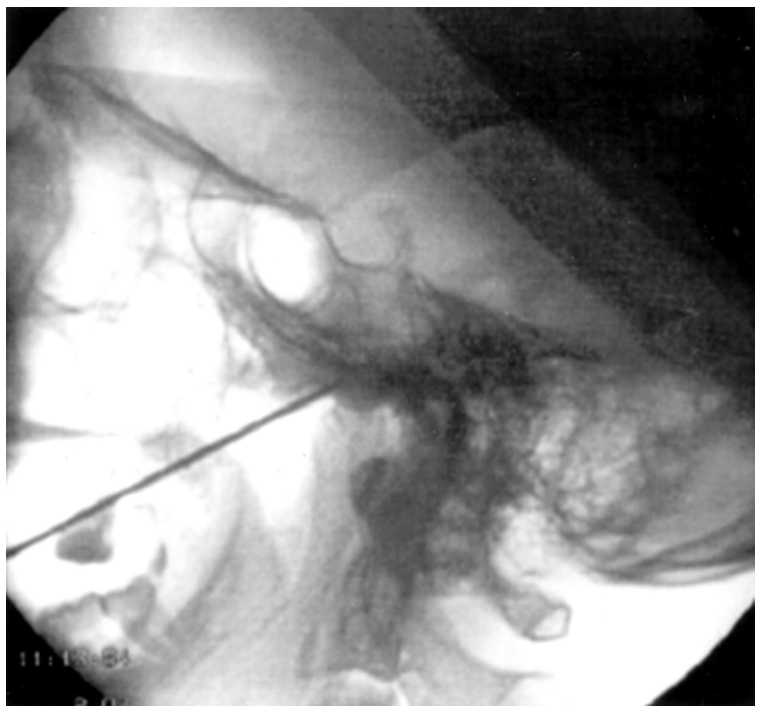

C

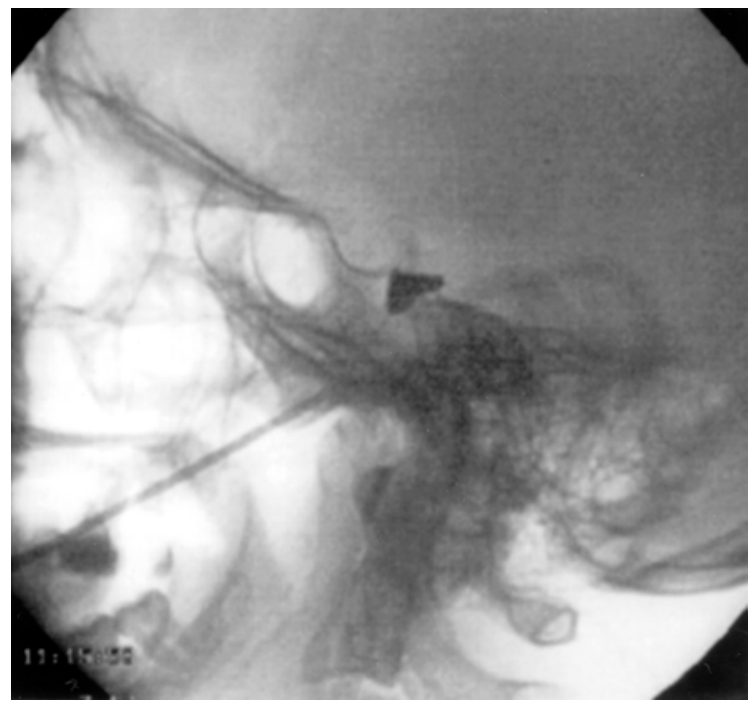

B

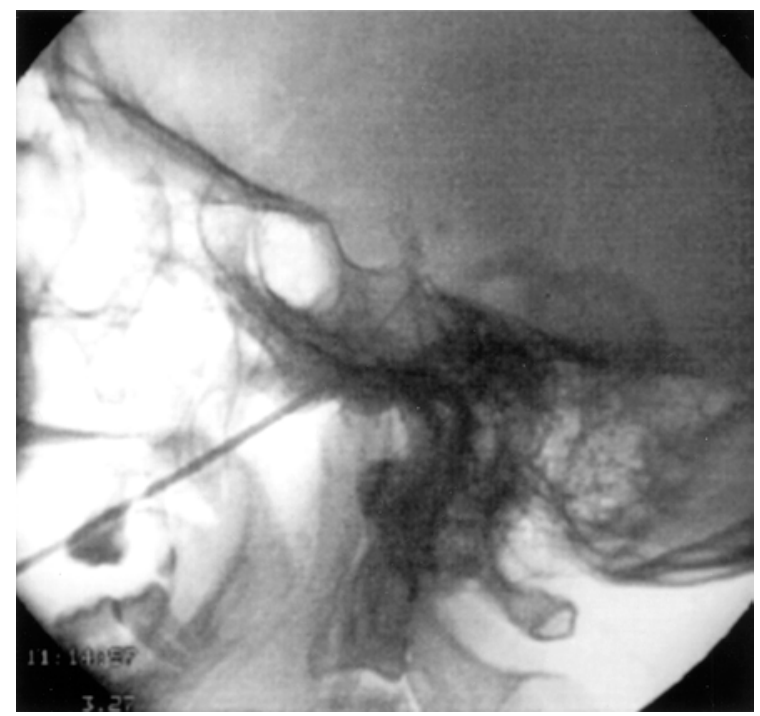

D

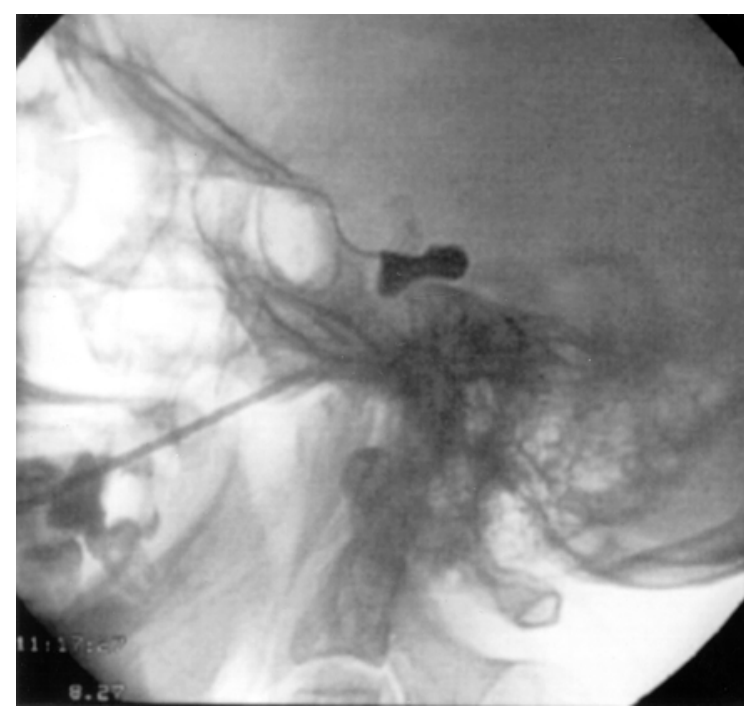

Figura 2 - Reprodução fotográfica das imagens radiográficas da execução do procedimento de compressão do gânglio de Gasser com balão.

A: Observa-se a agulha penetrando no forame oval;

B: Extremidade do cateter no plano paralelo ao clivo;

C: Distensão do balão com $0,7 \mathrm{ml}$ de contraste iodado induzindo a conformação de pêra;

D: Balão com conformação de ampulheta.

As associações envolvendo variáveis qualitativas foram avaliadas com o Teste Exato de Fischer, uma vez que as freqüências esperadas foram muito baixas para a utilização do teste qui-quadrado. Em alguns casos, optou-se pela exclusão de categorias com baixa freqüência para melhorar a confiabilidade dos testes.

Para análise dos volumes dos balões, utilizou-se o teste não paramétrico de Mann-Whitney, como alternativa ao teste $\mathrm{t}$-Student, porque os dados não seguiram distribuição normal. Como o número de doentes foi pequeno, os resultados observados foram indicativos, devendo, portanto, haver cautela quando realizar-se inferências e interpretações. Os resultados considerados "tendência" foram valorizados, pois as diferenças indicadas em amostras pequenas, muitas vezes são comprovadas quando se analisam amostras maiores.

\section{Resultados}

Todos os doentes apresentavam dor intensa em choque na escala analógica verbal e zonas de gatilho. 
Não houve relato de ocorrência de neuralgia do trigêmeo em seus familiares. Acarbamazepina havia sido utilizada para o tratamento de todos os doentes, a difenil-hidantoína em 10, amitriptilina em 13 e o baclofeno, em 2. Não foram evidenciadas anormalidades neurológicas nos doentes dessa casuística.

Quatorze (35\%) doentes eram do sexo masculino e 26 (65\%), do feminino. A dor localizou-se à direita em 20 casos, à esquerda em 19 e era bilateral em 1 .

Devido à miscigenação da população estudada, não foi possível avaliar a distribuição dos doentes quanto aos grupos raciais.

As idades variaram de 39 a 83 anos. A média das idades foi 65,6 anos, sendo o desvio padrão (DP) 8,9 anos. Dezenove $(47,5 \%)$ doentes apresentavam idade de 61 a 70 anos; 9 (22,5\%), 51 a 60 anos; outros $9(22,5 \%)$, 71 a 80 anos; e $2(5 \%)$, mais de 80 anos. Apenas 1 $(2,5 \%)$ doente apresentava menos de 40 anos de idade. Na tabela 1 está relacionada a distribuição dos doentes quanto às faixas etárias.

\begin{tabular}{ccc}
\hline \multicolumn{3}{c}{ Tabela 1} \\
Distribuição & $\begin{array}{c}\text { dos doentes segundo } \\
\text { etárias (em anos) }\end{array}$ & \\
\hline Intervalo das & Número & Percentagem \\
idades (em anos) & de doentes & \\
\hline$<40$ & 1 & 2,5 \\
$41-50$ & - & - \\
$51-60$ & 9 & 22,5 \\
$61-70$ & 19 & 47,5 \\
$71-80$ & 9 & 22,5 \\
$>80$ & 2 & 5,0 \\
Total & 40 & 100 \\
\hline
\end{tabular}

Média: 65,6 anos; DP = 8,9 anos

As queixas álgicas duraram de menos de dois anos a mais de oito anos, sendo que $80 \%$ dos doentes apresentavam dor durando entre três e oito anos. A média foi 5,75 anos e o desvio padrão, 2,48 anos. Na tabela 2 está relacionada a distribuição dos doentes quanto ao tempo de duração das queixas álgicas.

\begin{tabular}{ccc}
\hline \multicolumn{3}{c}{ Tabela } \\
Distribuição dos doentes quanto ao periodo de \\
duração das \\
Tueixas álgicas \\
\hline dempo de duração & Número & Percentagem \\
\hline$<2$ & de doentes & \\
\hline-5 & 3 & 7,5 \\
$6-8$ & 17 & 42,5 \\
$>8$ & 15 & 37,5 \\
Total & 5 & 12,5 \\
\hline
\end{tabular}

* No doente com dor bilateral, considerou-se a duração do quadro inaugural Média: 5,75 anos; DP = 2,48 anos
O ramo maxilar foi acometido em três $(7,3 \%)$ doentes; o ramo mandibular, em dois (4,9\%); os nervos oftálmico e maxilar, em dois (4,9\%); os nervos maxilar e mandibular, em $30(73,2 \%)$ e os nervos oftálmico, maxilar e mandibular, em quatro $(9,7 \%)$. O ramo oftálmico isoladamente não foi acometido. Na tabela 3 está relacionada a distribuição dos doentes quanto ao ramo acometido pela dor.

\begin{tabular}{lcc}
\hline \multicolumn{3}{c}{ Tabela 3} \\
Distribuição dos doentes segundo o ramo \\
acometido pela & dor \\
\hline \multicolumn{1}{c}{ Ramo acometido } & Número & Percentagem \\
\hline Oftálmico (V1) & - & - \\
Maxilar(V2) & 3 & 7,3 \\
Mandibular (V3) & 2 & 4,9 \\
Oftálmico/Maxilar(V1/V2) & 2 & 4,9 \\
Maxilar/Mandibular (V2/V3) & 30 & 73,2 \\
Oftálmico/Maxilar/Mandibular (V1/V2/V3) & 4 & 9,7 \\
Total & 41 & 100 \\
\hline
\end{tabular}

Quarenta doentes foram submetidos a 50 procedimentos. Em 30 doentes foi realizado um procedimento, em 1 foi bilateral e em 9 foram realizados dois procedimentos.

$\mathrm{O}$ volume de contraste injetado no balão variou de 0,7 a $1 \mathrm{ml}$ (média $=0,87 \mathrm{ml} ; \mathrm{DP}=0,1$ ); foi de $0,7 \mathrm{ml} \mathrm{em} 4$ doentes; $0,8 \mathrm{ml} \mathrm{em} \mathrm{13;0,9} \mathrm{ml} \mathrm{em} \mathrm{13;} \mathrm{e} \mathrm{1,0} \mathrm{ml} \mathrm{em} 11$. Na tabela 4 está relacionada a distribuição dos volumes de contraste injetados durante o primeiro procedimento.

\begin{tabular}{ccc}
\hline \multicolumn{3}{c}{ Tabela } \\
Distribuição dos volumes de contraste injetados \\
durante o primeiro procedimento
\end{tabular}

Média: 0,87 ml; DP = 0,1 ml

Foi induzida a forma em ampulheta no balão durante $20(48,8 \%)$ procedimentos, a forma em pêra em 18 $(43,9 \%)$ e a forma oval em $3(7,3 \%)$. Na tabela 5 estão apresentadas as conformações adquiridas pelo balão durante o primeiro procedimento.

\begin{tabular}{ccc}
\hline \multicolumn{3}{c}{ Tabela } \\
\multicolumn{3}{c}{$\begin{array}{c}\text { Distribuição da forma do balão durante } \\
\text { o primeiro procedimento }\end{array}$} \\
\hline Forma do balão & Número de procedimentos & Percentagem \\
\hline Ampulheta & 20 & 48,8 \\
Pêra & 18 & 43,9 \\
Oval & 3 & 7,3 \\
Total & 41 & 100 \\
\hline
\end{tabular}


Após a primeira cirurgia, ocorreu alívio da dor em $37(90,26 \%)$ hemifaces, melhora em $2(4,87 \%)$ e ausência de melhora em 2 (4,87\%) hemifaces.

Na tabela 6 está representada a distribuição dos resultados quanto à melhora ou não da dor na hemiface tratada.

\begin{tabular}{ccc}
\hline \multicolumn{3}{c}{ Tabela 6} \\
Distribuição dos resultados do tratamento em cada \\
hemiface, após o primeiro procedimento
\end{tabular}

Em todos os doentes ocorreu redução da freqüência dos batimentos cardíacos e hiperemia conjuntival durante a punção do forame oval e enchimento do balão.

Após o primeiro procedimento, em $28(68,4 \%)$ hemifaces ocorreu hipoestesia discreta, em 12 (29,2\%), hipoestesia moderada e em $1(2,4 \%)$ não ocorreu déficit sensitivo. Na tabela 7 são apresentadas as alterações sensitivas das hemifaces dos doentes tratados.

Tabela 7

Distribuição dos doentes quanto ao grau de hipoestesia em cada hemiface observado durante o periodo pós-operatório

\begin{tabular}{ccc}
\multicolumn{3}{c}{ após o primeiro procedimento } \\
\hline $\begin{array}{c}\text { Intensidade da } \\
\text { hipoestesia }\end{array}$ & $\begin{array}{c}\text { Número de } \\
\text { procedimentos }\end{array}$ & Percentagem \\
\hline Discreta & 28 & 68,4 \\
Moderada & 12 & 29,2 \\
Ausente & 1 & 2,4 \\
Total & 41 & 100 \\
\hline
\end{tabular}

A hipoestesia induzida foi discreta em 16 hemifaces e moderada em 4, quando a forma do balão foi em ampulheta; foi discreta em 10 e moderada em 8 , quando o balão adquiriu a forma de pêra; foi discreta em 2 e ausente em 1 , quando o balão apresentou a forma oval (Tabela 8).

Algum grau de déficit funcional da musculatura mastigatória ipsilateral foi identificado após todos os procedimentos; em nenhum foi intenso e, em apenas três, foi incômodo, sendo mais freqüente quando o balão adquiriu a forma em ampulheta. As anormalidades cederam sem que medidas terapêuticas fossem adotadas, antes do término da quarta semana de acompanhamento. Na tabela 9 é apresentada a distribuição dos déficits funcionais da musculatura mastigatória segundo a forma adquirida pelo balão.

Ocorreu diplopia transitória durante dois procedimentos, erupções pelo vírus do herpes simples em quatro procedimentos e hematoma facial ipsilateral à punção em três.

A forma em pêra do balão foi observada em $18(43,9 \%)$ operações e proporcionou alívio da dor em $17(94,4 \%)$ e melhora em 1 (5,6\%). Nas 17 ocasiões em que ocorreu alívio da dor, em $10(58,8 \%)$ os doentes deixaram de utilizar medicação e em $7(41,2 \%)$ reduziram a dose, não aceitando a proposta de deixar seu uso. A forma em ampulheta do balão ocorreu em $20(48,8 \%)$ operações e promoveu alívio da dor em todos; 13 (65\%) desses reduziram a medicação antineurálgica, mas recusaramse a suspendê-la, e 7 (35\%) descontinuaram seu uso. A forma oval foi induzida em 3 (7,3\%) ocasiões; em 1 doente houve melhora e em 2, não. Esses dois últimos doentes foram submetidos a outro procedimento, nas primeiras 24 horas após o primeiro, com compressão durando 120 segundos, em que foi induzida a forma do balão em ampulheta, do que resultou alívio da dor. $\mathrm{O}$ vigésimo

\begin{tabular}{|c|c|c|c|c|c|c|c|}
\hline \multicolumn{8}{|c|}{$\begin{array}{c}\text { Tabela } 8 \\
\text { Distribuição dos déficits sensitivos em relação à forma do balão após o primeiro procedimento }\end{array}$} \\
\hline \multicolumn{8}{|c|}{ Forma do balão } \\
\hline Déficit sensitivo & Pêra & $\%$ & Ampulheta & $\%$ & Oval & $\%$ & Total \\
\hline Discreto & 10 & 24,4 & 16 & 39,0 & 2 & 4,9 & $29(70,7 \%)$ \\
\hline Moderado & 8 & 19,5 & 4 & 9,8 & - & - & $12(29,3 \%)$ \\
\hline Ausente & - & - & - & - & 1 & 2,4 & $1(2,4 \%)$ \\
\hline Intenso & - & - & - & - & - & - & - \\
\hline Total & 18 & 43,9 & 20 & 48,8 & 3 & 7,3 & $41(100 \%)$ \\
\hline
\end{tabular}

Tabela 9

Distribuição dos déficits funcionais da musculatura mastigatória em relação às formas do balão, após o primeiro procedimento

\begin{tabular}{|c|c|c|c|c|c|c|c|}
\hline \multicolumn{8}{|c|}{ Forma do balão } \\
\hline Déficit motor & Pêra & $\%$ & Ampulheta & $\%$ & Oval & $\%$ & Total \\
\hline Discreto & 12 & 29,2 & 18 & 44 & 1 & 2,4 & $31(75,6 \%)$ \\
\hline Moderado & 6 & 14,6 & 2 & 4,9 & 2 & 4,9 & $10(24,4 \%)$ \\
\hline Intenso & - & - & - & & - & & - \\
\hline Total & 18 & 43,9 & 20 & 48,8 & 3 & 7,3 & $41(100 \%)$ \\
\hline
\end{tabular}


segundo paciente dessa série apresentou neuralgia bilateral, realizando-se o procedimento com cateter $4 \mathrm{~F}$ à direita, lado de dor mais intensa, e com o $3 \mathrm{~F}$ à esquerda, que era o lado de dor menos intensa, por não dispormos de outro cateter $4 \mathrm{~F}$. O balão $4 \mathrm{~F}$ adquiriu a forma de pêra e obteve-se alívio da dor, enquanto o balão $3 \mathrm{~F}$ adquiriu a forma oval e não promoveu alívio da dor. Na tabela 10 é apresentada a distribuição dos resultados dos procedimentos em relação às formas do balão.

Excluídos os três casos em que a forma oval do balão foi observada, concluímos que não houve relação estatisticamente significante entre a forma do balão, em ampulheta ou em pêra, e as alterações motoras e sensitivas e a natureza do alívio após os procedimentos, segundo o Teste Exato de Fisher (Tabela 11).

Ocorreu tendência (valores de p entre 0,05 e 0,10 ) de, nos procedimentos em que a forma induzida no balão foi em pêra, ocorrer mais freqüentemente anormalidades motoras e sensitivas moderadas que nos procedimentos em que o balão adquiriu a forma de ampulheta. $\mathrm{O}$ teste estatístico indicou haver tendência $(\mathrm{p}=0,088)$ de a aquisição da forma em ampulheta proporcionar maior freqüência de alívio da dor.

Os volumes injetados no balão tiveram quatro valores $(0,7 \mathrm{ml} ; 0,8 \mathrm{ml} ; 0,9 \mathrm{ml} \mathrm{e} \mathrm{1,0} \mathrm{ml})$. Apesar de o volume ser uma variável quantitativa, houve dificuldade para utilização dos testes estatísticos, uma vez que estes supõem normalidade das observações, o que não se aplicou a esta amostra. Optou-se, então, pela análise do volume de duas maneiras: consideraram-se os valores originais e compararam-se as médias com o teste não paramétrico de Mann-Whitney, alternativo ao teste $t$-Student, com a suposição de que a distribuição normal não poderia ser assumida (Tabela 12).

Os doentes foram divididos em um grupo em que os volumes foram de $0,7 \mathrm{ml} \mathrm{e} 0,8 \mathrm{ml}$, e outro em que os volumes foram de $0,9 \mathrm{ml} \mathrm{e} \mathrm{1,0} \mathrm{ml}$. Esses dados, agrupados, foram analisados em relação aos déficits neurológicos induzidos e aos resultados dos procedimentos, comparando-se as distribuições segundo o Teste Exato de Fisher (Tabela 13).

Comparando-se as médias, verificou-se que, quando ocorreu déficit motor mastigatório moderado, os volumes foram menores que quando ocorreu disfunção discreta $(\mathrm{p}=0,022)$; a diferença média foi da ordem de 0,08 ml. Observou-se, também, que a hipoestesia moderada ocorreu, mais freqüentemente, quando o volume injetado foi maior $(\mathrm{p}=0,008$, diferença de $0,09 \mathrm{ml}$ ). Não houve diferença de volumes nas operações em que ocorreu alívio ou melhora

\begin{tabular}{ccccc}
\hline & \multicolumn{5}{c}{ Tabela 10 } \\
& Distribuição dos resultados quanto à forma do baláo após a primeira operação & \\
\hline Forma do balão & Alívio da dor & Melhora & Sem melhora & Total \\
\hline Pêra & $17(41,4 \%)$ & $1(2,4 \%)$ & - & $18(43,9 \%)$ \\
Ampulheta & $20(48,8 \%)$ & - & - & $20(48,8 \%)$ \\
Oval & - & $1(2,4 \%)$ & $2(4,8 \%)$ & $3(7,3 \%)$ \\
Total & $37(90,2 \%)$ & $2(4,8 \%)$ & $2(4,8 \%)$ & $41(100 \%)$ \\
\hline
\end{tabular}

Tabela 11

Distribuição dos procedimentos correlacionando-se os graus de déficits da motricidade mastigatória e da sensibilidade e os resultados do tratamento em relação às formas adquiridas pelo balão

\begin{tabular}{|c|c|c|c|c|}
\hline \multicolumn{5}{|c|}{ Forma do balão } \\
\hline Variável & $\begin{array}{c}\text { Pêra } \\
(\mathrm{N}=17)(\%)\end{array}$ & $\begin{array}{l}\text { Ampulheta } \\
(\mathrm{N}=\mathbf{2 0})(\%)\end{array}$ & $\begin{array}{c}\text { Oval } \\
(\mathrm{N}=3)(\%)\end{array}$ & $\begin{array}{c}\text { Teste Exato } \\
\text { de Fisher } \\
\text { (p)* }\end{array}$ \\
\hline \multicolumn{5}{|l|}{ Déficit motor mastigatório } \\
\hline Discreto & $11(64,7 \%)$ & $18(90,0 \%)$ & $1(33,3 \%)$ & 0,072 \\
\hline Moderado & $6(35,3 \%)$ & $2(10,0 \%)$ & $2(66,7 \%)$ & \\
\hline \multicolumn{5}{|l|}{ Sensibilidade facial } \\
\hline Hipoestesia discreta & $9(52,9 \%)$ & $16(80,0 \%)$ & $3(100 \%)$ & 0,081 \\
\hline Hipoestesia moderada & $8(47,1 \%)$ & $4(20,0 \%)$ & - & \\
\hline \multicolumn{5}{|l|}{ Resultado } \\
\hline Alívio & $14(82,4 \%)$ & $20(100 \%)$ & $1(33,3 \%)$ & \\
\hline Melhora & $3(17,6 \%)$ & - & $1(33,3 \%)$ & 0,088 \\
\hline Inalterado & - & - & $1(33,3 \%)$ & \\
\hline
\end{tabular}

*Os testes estatísticos desconsideraram os procedimentos em que a conformação oval do balão foi induzida 


\begin{tabular}{|c|c|c|c|}
\hline \multicolumn{4}{|c|}{$\begin{array}{c}\text { Distribuição dos procedimentos em relação à intensidade do déficit motor mastigatório e sensitivo e o } \\
\text { resultado do tratamento em relação aos volumes médios injetados no balão }\end{array}$} \\
\hline Variável & Volume médio (erro padrão) & Teste de Mann-Whitney (p) & Diferença média (em ml) \\
\hline \multicolumn{4}{|l|}{ Déficit motor } \\
\hline Discreto $(\mathrm{N}=30)$ & $0,89(0,001)$ & 0,022 & 0,08 \\
\hline Moderado $(\mathrm{N}=10)$ & $0,81(0,003)$ & & \\
\hline \multicolumn{4}{|l|}{ Déficit sensitivo } \\
\hline Hipoestesia discreta $(\mathrm{N}=28)$ & $0,84(0,002)$ & 0,008 & 0,09 \\
\hline Hipoestesia moderada $(\mathrm{N}=12)$ & $0,93(0,002)$ & & \\
\hline \multicolumn{4}{|l|}{ Resultados } \\
\hline Alívio $(\mathrm{N}=35)$ & $0,88(0,002)$ & $0,247^{*}$ & 0,05 \\
\hline Melhora $(\mathrm{N}=4)$ & $0,83(0,003)$ & & \\
\hline
\end{tabular}

*Foi excluído o doente que não apresentou melhora após injeção de $0,8 \mathrm{ml}$ de contraste no balão

Tabela 13

Distribuição dos procedimentos correlacionando-se a intensidade do déficit da motricidade mastigatória e da sensibilidade facial e os resultados em relação aos volumes de distensão do balão com $0,7 \mathrm{ml}$ e $0,8 \mathrm{ml}$ ou $0,9 \mathrm{ml}$ e $1,0 \mathrm{ml}$

\begin{tabular}{|c|c|c|c|}
\hline \multicolumn{4}{|c|}{ Volume } \\
\hline Variável & $\begin{array}{c}0,7 \mathrm{ml} / 0,8 \mathrm{ml} \\
(\mathrm{N}=17) \\
(\%)\end{array}$ & $\begin{array}{c}0,9 \mathrm{ml} / 1,0 \mathrm{ml} \\
(\mathrm{N}=23) \\
(\%)\end{array}$ & $\begin{array}{c}\text { Teste Exato } \\
\text { de Fisher } \\
\text { (p) }\end{array}$ \\
\hline \multicolumn{4}{|l|}{ Déficit motor mastigatório } \\
\hline Discreto & $9(52,9 \%)$ & $21(91,3 \%)$ & 0,008 \\
\hline Moderado & $8(47,1 \%)$ & $2(8,7 \%)$ & \\
\hline \multicolumn{4}{|l|}{ Déficit sensitivo } \\
\hline Hipoestesia discreta & $15(88,2 \%)$ & $13(56,5 \%)$ & 0,032 \\
\hline Hipoestesia moderada & $2(11,8 \%)$ & $10(43,5 \%)$ & \\
\hline \multicolumn{4}{|l|}{ Resultados } \\
\hline Alívio & $13(76,5 \%)$ & $22(95,7 \%)$ & \\
\hline Melhora & $3(17,6 \%)$ & $1(4,3 \%)$ & $0,179 *$ \\
\hline Inalterado & $1(5,9 \%)$ & - & \\
\hline
\end{tabular}

* Foi desconsiderado o doente que não apresentou melhora após insuflação do balão com $0,8 \mathrm{ml}$ de contraste

dador. Entretanto, esta comparação foi comprometida devido ao fato de que apenas em quatro ocasiões ocorreu melhora da dor. As análises alternativas reforçam as conclusões de que volumes menores foram os que proporcionaram déficit motor moderado $(p=0,008)$ e hipoestesia discreta $(p=0,032)$.

Não foi constatada correlação entre hipoestesia e os resultados (Tabela 14).

\begin{tabular}{|c|c|c|c|}
\hline $\begin{array}{r}\text { Distribu } \\
\text { nature }\end{array}$ & $\begin{array}{r}\text { Ta } \\
\text { dos proced } \\
\text { resultados } \\
\text { sensitiv }\end{array}$ & $\begin{array}{l}14 \\
\text { tos correl } \\
\text { intensidad } \\
\text { iduzidos }\end{array}$ & $\begin{array}{l}\text { ando-se a } \\
\text { déficits }\end{array}$ \\
\hline & Déficit s & ivo facial & \\
\hline Variável & $\begin{array}{c}\text { Discreto } \\
(\mathrm{N}=28) \\
(\%)\end{array}$ & $\begin{array}{c}\text { Moderado } \\
(\mathrm{N}=12) \\
(\%)\end{array}$ & $\begin{array}{c}\text { Teste Exato } \\
\text { de Fisher } \\
\text { (p) }\end{array}$ \\
\hline Alívio da dor & $23(82,1 \%)$ & $12(100 \%)$ & \\
\hline Melhora & $4(14,3 \%)$ & - & $0,213^{*}$ \\
\hline Sem melhora & $1(3,6 \%)$ & - & \\
\hline
\end{tabular}

*Foi excluído o doente sem melhora
Nos seis doentes que apresentaram recidiva, nos dois em que não houve melhora e em um com melhora parcial, totalizando, nove casos, foi realizada outra intervenção com duração de 120 segundos. Em nenhum havia hipoestesia na face decorrente do primeiro procedimento. As recidivas ocorreram de 6 a 42 meses após a primeira compressão, sendo quatro durante os primeiros 24 meses, uma aos 36 meses e uma aos 42 meses. Em dois a forma do balão foi oval, em três em pêra e em um, em ampulheta (Tabela 15).

$\mathrm{O}$ volume de injetado no balão, no segundo procedimento, variou de $0,7 \mathrm{ml} \mathrm{a} 1,0 \mathrm{ml}$ (média de $0,85 \mathrm{ml}$ ) (Tabela 16).

Foi induzida a forma em ampulheta do balão em todos os nove pacientes submetidos a segunda operação. O segundo procedimento induziu hipoestesia discreta em dois doentes, moderada em sete, disestesias discretas, controladas com carbamazepina em dois, e gerou déficit moderado da musculatura mastigatória em seis doentes e discreto em três. Após o sexto mês de acompanhamento, não foi constatado déficit 
Tabela 15

\begin{tabular}{cc}
$\begin{array}{c}\text { Distribuição dos procedimentos quanto ao tempo decorrido } \\
\text { para ocorrência de recidiva da dor, em relação às formas } \\
\text { adquiridas pelo baláa na primeira cirurgia }\end{array}$ \\
\hline $\begin{array}{c}\text { Período decorrido após o } \\
\text { procedimento (em meses) }\end{array}$ & Forma do balão \\
\hline 6 & 1 (oval) \\
8 & 1 (oval) \\
16 & 1 (pêra) \\
24 & 1 (pêra) \\
36 & 1 (ampulheta) \\
42 & 1 (pêra) \\
Total & 6 \\
\hline
\end{tabular}

\begin{tabular}{|c|c|}
\hline \multicolumn{2}{|c|}{$\begin{array}{c}\text { Tabela } 16 \\
\text { Distribuição dos procedimentos quanto ao volume } \\
\text { de contraste injetado no balão durante } \\
\text { o segundo procedimento }\end{array}$} \\
\hline Volume (ml) & Número de doentes \\
\hline 0,7 & 1 \\
\hline 0,8 & 2 \\
\hline 0,9 & 2 \\
\hline 1,0 & 4 \\
\hline Total & 9 \\
\hline
\end{tabular}

motor em nenhum caso. Ocorreu alívio duradouro da dor nos nove doentes submetidos à segunda compressão. A medicação antineurálgica foi suspensa em sete doentes e reduzida em dois que não aceitaram sua suspensão. Os doentes submetidos ao segundo procedimento foram acompanhados durante 6 a 36 meses.

O período de acompanhamento variou de 6 a 48 meses: 9 doentes foram acompanhados durante 6 meses; 3, durante 7 meses; 1 , durante 8 meses; 1 , durante 10 meses; 3 , durante 12 meses; 6 , durante 18 meses; 4, durante 24 meses; 1 , durante 25 meses; 1 , durante 26 meses; 1 , durante 28 meses; 4 , durante 30 meses; 2, durante 42 meses; e 4 , durante 48 meses (Quadro 1).

A taxa final de recidiva da dor após a CGGB foi de $15 \%$ em 48 meses.

\section{Discussão}

Dor ainda é um sério problema na sociedade moderna. Implica sofrimento tanto para os doentes como para seus cuidadores, agrava as condições clínicas e psíquicas daqueles que dela padecem, aumenta o risco de fatalidades e incapacidades e gera prejuízos com as óbvias repercussões sociais e econômicas. "A ocorrência de dor, especialmente a crônica, é crescente, em decorrência dos novos hábitos de vida, da maior longevidade do indivíduo, do prolongamento da sobrevida dos doentes com afecções clínicas naturalmente fatais ou muito incapacitantes, das modificações do meio ambiente e, provavelmente, do decréscimo da tolerância ao sofrimento do homem e da aplicação dos novos conceitos que traduzem seu significado" 105,106 .

Fatores genéticos, constitucionais, ambientais, sexo e idade intervêm na ocorrência da dor ${ }^{103}$. A dor neuropática é comum em indivíduos que procuram assistência médica. Supõe-se que a ocorrência das neuropatias seja muito variada nas diferentes regiões do mundo, nos diferentes países e nas diferentes comunidades. Entretanto, dados epidemiológicos sobre a ocorrência de dor em neuropatias são escassos e incompletos. Isso é devido, em parte, ao fato de os estudos sobre a incidência e prevalência da dor neuropática serem difíceis porque implicam a realização de exames físicos instrumentalizados, o que os torna muito complexos e dispendiosos ${ }^{106,107}$. Poucos relatos epidemiológicos foram publicados sobre a neuralgia do trigêmeo. Estudos realizados nos Estados Unidos constataram a prevalência de 155 casos para 1 milhão de habitantes ${ }^{9,70}$. Buscaino ${ }^{22}$ encontrou a mesma prevalência na Itália. Yoshimasu e cols. ${ }^{115}$, avaliando a ocorrência da neuralgia do trigêmeo em Rochester (Estados Unidos), entre 1945 e 1969, observaram incidência anual de 4,3 casos novos por $100 \mathrm{mil}$ habitantes. Houve maior incidência na população do sexo feminino: 5 casos novos por ano a cada $100 \mathrm{mil}$ mulheres e 2,7 casos novos por ano a cada $100 \mathrm{mil}$ homens. Demonstraram que a incidência aumenta com o progredir da idade, mantendo-se constante a seguir. Na presente casuística, todos os 40 doentes apresentaram neuralgia essencial do trigêmeo rebelde ao tratamento clínico.

Não há referências a respeito da incidência da neuralgia do trigêmeo nas diferentes raças. A distribuição racial dos doentes verificada no presente estudo, provavelmente, reflete a miscigenação da população que freqüenta o hospital onde o trabalho foi realizado ${ }^{104}$.

A média das idades dos doentes da presente casuística foi 65,6 anos; ocorreu predomínio da neuralgia na sexta à oitava décadas de vida, distribuição esta que concorda com a apresentada em outras publicações s $^{3,88,104,115}$. Em apenas um (2,5\%) doente, a neuralgia manifestou-se antes dos 40 anos de idade. A média etária dos doentes, no início da sintomatologia, situa-se, geralmente, entre a quinta e oitava décadas, na maioria das casuísticas ${ }^{3,84,88,104,115}$. Poucos doentes apresentam idade inferior a 30 anos $^{47,49,96}$. Harris $^{47}$, em 1936, descreveu um caso de neuralgia do trigêmeo iniciando-se aos 16 meses e Barclay (apud Penman $^{79}$ ) em um doente com dez anos de idade. Na casuística de 
Rushton e Mac Donald ${ }^{87}$, a idade foi inferior a 40 anos em somente $12,3 \%$ dos doentes e, na de Henderson ${ }^{49}$, $1 \%$ dos doentes relatou que a dor teve início entre $16 \mathrm{e}$ 29 anos de idade.

O período médio de duração da sintomatologia nos doentes da presente casuística foi de 5,8 anos, sendo, em alguns casos, superior a dez anos, o que traduz o prolongado sofrimento gerado pela afecção e o elevado custo decorrente do seu tratamento, compensações e inabilidades. A dor em doentes com neuralgia do trigêmeo é considerada a de maior magnitude possível no ser humano ${ }^{104}$. Apesar de os episódios dolorosos serem de curta duração, o sofrimento que causa justifica a adoção de atitudes terapêuticas enérgicas e imediatas.

$\mathrm{Na}$ presente casuística houve predomínio dos doentes do sexo feminino que perfez $65 \%$ dos casos, dado este que coincide com o de outros auto$\mathrm{res}^{41,85,96,21,104}$. Existe pequeno predomínio da neuralgia do trigêmeo nos indivíduos do sexo feminino; $51 \%$ a $66 \%$ dos doentes é do sexo feminino ${ }^{21,41,85,96,104 ;} 82,6 \%$ a $83 \%$ dos casos de neuralgia bilateral ocorre nos indivíduos do sexo feminino ${ }^{96}$.

A neuralgia do trigêmeo não ocorreu em outros membros da família na presente casuística. Casos familiares de neuralgia do trigêmeo são esporá$\operatorname{dicos}^{4,29,39,50,96}$; variam de $2,6 \%$ a $6 \%{ }^{64,87}$. Nos casos familiares há maior número de doentes com neuralgia bilateral ${ }^{7}$. Herança autossômica dominante, autossômica recessiva e, possivelmente, ligada ao gene $\mathrm{X}$, podem estar envolvidas na ocorrência de quadros familiares ${ }^{28}$. A dor costuma ocorrer do mesmo lado nos casos familiares $^{8} \mathrm{e}$, mais precocemente, nos descendentes ${ }^{46}$. Teixeira ${ }^{104}$, em 1985, relatou a ocorrência de casos familiares de neuralgia do trigêmeo em $1 \%$ de seus doentes. Braga e cols. ${ }^{14}$, em1986, relataram quatro casos de neuralgia do trigêmeo acometendo dois irmãos e duas irmãs, com início da dor entre 24 e 31 anos.

Houve predomínio dos doentes com acometimento concomitante dos nervos maxilar e mandibular (73,2\% dos casos), seguindo-se o acometimento concomitante dos nervos oftálmico, maxilar e mandibular (9,7\%); do ramo maxilar isoladamente (7,3\%); do ramo mandibular, isoladamente, ou dos nervos oftálmico e maxilar associadamente $(4,9 \%)$. Esses achados estão de acordo com as casuísticas de Henderson ${ }^{49}$, White e Sweet ${ }^{113} \mathrm{e}$ Teixeira ${ }^{104}$ que encontraram maior acometimento dos nervos maxilar e mandibular e, raramente, do ramo oftálmico isoladamente, e com as de Rushton e Mc Donald ${ }^{87}$ e Stookey e Ransohoff ${ }^{96}$ que relataram ser raro o acometimento concomitante dos nervos oftálmico e mandibular, poupando o ramo maxilar.

Houve, na presente casuística, acometimento similar de ambas as hemifaces, fato que não está de acordo com o observado por alguns autores ${ }^{49}$. Predomínio da dor à direita foi relatado em algumas casuísticas ${ }^{104}$.

Não há relação entre sexo, idade, raça, dominância hemisférica e lateralidade das lesões. A neuralgia do trigêmeo é bilateral em $0,3 \%$ a $7 \%$ dos casos; excepcionalmente, a dor inicia-se concomitantemente em ambos os lados. Na maioria das vezes, a dor contralateral surge alguns anos após o início do quadro. O comprometimento de territórios simétricos é freqüente, principalmente quando o ramo mandibular for afetado. Foi notada associação de neuralgia do trigêmeo bilateral com esclerose múltipla ${ }^{26,31,47,59,85,87,113}$. Em apenas um $(2,5 \%)$ doente da presente casuística a dor foi bilateral, coincidindo com a média observada em outras casuísticas $^{26,30,38,47,104,115}$.

Fatores desencadeantes da dor e ocorrência de zonas de gatilho estiveram presentes em $100 \%$ dos doentes da presente casuística. Este valor é superior ao descrito por outros autores, que os constataram em apenas $50 \%$ a $72 \%$ dos casos ${ }^{104,115}$. Segundo Alajouanine e Thurel $^{2}$, o desencadeamento da dor pela estimulação das zonas de gatilho é que caracteriza a neuralgia do trigêmeo e constitui o melhor elemento para o seu diagnóstico.

Não foram observadas anormalidades neurológicas nos doentes da presente casuística. Este dado está de acordo com o conceito de que não devem ser evidenciadas alterações da função trigeminal em doentes com neuralgia do trigêmeo ${ }^{96}$. Entretanto, hipoestesia facial e hiporreflexia corneana foram observadas em até $63,3 \%$ dos casos em algumas casuísticas ${ }^{56,64,79,104}$. O reflexo córneo-palpebral pode estar hipoativo, principalmente em casos de dor acometendo o ramo oftálmico ou o ramo maxilar ${ }^{98,113}$. Paresia da musculatura mastigatória homolateral também podem ocorrer ${ }^{54}$. Harris $^{47}$, em1936, notou que quando a dor recorre repetidamente pode ocorrer hipoestesia da face. Lewy e Grant ${ }^{64}$, em 1938, observaram que $80 \%$ de seus doentes com neuralgia trigeminal apresentavam anormalidades motoras e dor com características neurálgicas na região braquial, intercostal e ciática e que havia antecedente pessoal ou familiar de enxaqueca em $20 \%$ dos casos, e de doença de Parkinson em 14\%. Cushing ${ }^{26}$ descreveu a associação de neuralgia do trigêmeo com espasmo hemifacial e denominou esta síndrome de tic convulsive. Essa associação ocorre em até 3\% dos $\operatorname{casos}^{3,26,40}$. Teixeira ${ }^{104}$ descreveu esta condição em 11,8\% dos doentes com neuralgia do trigêmeo bilateral. A associação de neuralgia do trigêmeo com o do glossofaríngeo ocorre em cerca de $1 \%$ dos casos ${ }^{104}$, mas não foi observada na presente casuística. Thurel ${ }^{110}$ descreveu um caso de neuralgia do trigêmeo associada a espasmo facial. É possível que o espasmo hemifacial e a neuralgia do trigêmeo e do glossofaríngeo tenham a 
mesma fisiopatologia ${ }^{41,82,90,104}$, o que justifica estas combinações. Segundo Stookey e Ransohoff ${ }^{96} \mathrm{e}$ White e Sweet ${ }^{113}$, sempre que houver déficit sensitivo na face é necessário pesquisar a possibilidade de ocorrência de lesões expansivas nas vias ou unidades trigeminais.

Vários procedimentos podem contribuir para reduzir a dor e o sofrimento; a dificuldade para o manejo da dor não reside apenas no tratamento sintomático, mas, também, na identificação e modificação dos fatores concorrentes para sua expressão e a correção dos desajustamentos que contribuem para o sofrimento. A pesquisa das etiologias e das nosologias da dor, portanto, é fundamental para a instalação das medidas analgésicas apropriadas ${ }^{108}$.

Em todos os casos da presente casuística foi realizada TC do crânio. A TC de crânio pode, entretanto, ser normal em casos de processos expansivos nas vias trigeminais ${ }^{55}$. A RM do encéfalo foi realizada em três doentes com idade inferior a 50 anos para descartar outras condições sintomáticas ou anormalidades vasculares sugeridas no exame de CT. Segundo Hutchins e cols. ${ }^{52}$, a RM é o método de imagem de eleição para avaliação da neuralgia do trigêmeo, sendo superior à TC para avaliar a anatomia do tronco encefálico e do nervo trigêmeo e para detectar lesões que promovem neuralgia do trigêmeo, tais como, placas de esclerose múltipla, gliomas do tronco encefálico, acidentes vasculares encefálicos, vasos anômalos comprimindo a zona de entrada da raiz do nervo trigêmeo e tumores cisternais. Estudo angiográfico cerebral foi realizado em apenas três doentes, na presente casuística. Segundo Jannetta ${ }^{55}$, esse método de investigação não demonstra claramente a compressão neurovascular. No passado, o estudo angiográfico encefálico foi muito útil para a detecção de lesões expansivas intracranianas ${ }^{55}$; atualmente é indicado para o diagnóstico de afecções vasculares e, eventualmente, de tumores $23,63,71,74,78,95,114$. São encontradas anormalidades eletromiográficas da musculatura temporal e do masseter, especialmente em casos de neuralgia sintomática, mesmo quando o exame clínico é normal ${ }^{43,53,60,76,77,89}$. O estudo eletrofisiológico do reflexo do piscamento e do reflexo mentoniano ${ }^{11,43,60} \mathrm{e}$ potencial evocado somatossensitivo podem sofrer alterações em muitos doentes com dor facial ${ }^{11,12,95}$.

O exame do líquido cerebrospinal é utilizado para o diagnóstico de processos expansivos intracranianos intra e extra-axiais ${ }^{5,15,61,63}$. É, ainda, instrumento útil quando há suspeita de carcinomatose meníngea, diagnóstico e acompanhamento de afecções inflamatórias, infecciosas e parasitárias ${ }^{104}$. O exame do líquido cerebrospinal, realizado em um caso da presente casuística, foi normal. Sabe-se que pode ser normal mesmo em casos de lesões expansivas intracranianas ou esclerose múltipla ${ }^{5}$; pode revelar hiperproteinorraquia em doenças como a neurocisticercose $\mathrm{e}^{104}$.

Em casos de suspeita de neuropatia trigeminal, a pesquisa de doenças inflamatórias inespecíficas e da sífilis, com exames imunológicos e citológicos no sangue e no líquido cerebrospinal, é recomendada ${ }^{51,92}$.

$\mathrm{O}$ tratamento da dor visa à utilização de procedimentos que resultem na adequada interação biopsiquicossocial daqueles que dela padecem ${ }^{103}$. A eliminação das causas e conseqüências das síndromes dolorosas devem ser os alvos da equipe multiprofissional que atende os doentes com dor, visto que esta é relacionada às atitudes, ao psiquismo, ao estilo de vida, ao ambiente físico e social e às anormalidades estruturais ou funcionais dos doentes. Isso significa que, além do alívio da dor, a normalização das funções psíquicas e operacionais do organismo e a correção dos desajustamentos familiares e sociais que contribuem para o sofrimento devem ser os objetivos da assistência. A eliminação ou minimização dos desconfortos facilita e acelera o processo de recuperação, previne os efeitos adversos da dor e melhora a relação custo-benefício das intervenções. Além da adequação dos esquemas terapêuticos analgésicos, a orientação dos doentes, dos familiares e dos cuidadores sobre as razões e mecanismos da dor e sobre as razões e riscos dos procedimentos propostos para seu controle, melhora o resultado final do tratamento, amplia a confiança dos doentes na equipe de saúde, proporciona melhor adesão ao programa prescrito e contempla a correção dos conceitos mal elaborados sobre o uso de medidas analgésicas ${ }^{107}$. Essas foram as razões pelas quais todos os doentes da presente casuística foram esclarecidos sobre a necessidade, riscos e possíveis benefícios do procedimento operatório.

Os medicamentos analgésicos e adjuvantes, os procedimentos anestésicos e de medicina física e a psicoterapia, quando aplicados de modo racional, proporcionam melhora dos desconfortos e da qualidade de vida da maioria dos doentes com dor. É importante avaliar o resultado das intervenções analgésicas prévias e as atitudes dos doentes diante do uso de analgésicos, psicotrópicos, anticonvulsivantes e outras medicações, a ocorrência de anormalidades psiquiátricas e as expectativas dos doentes e da família em relação à dor, ao estresse e aos métodos terapêuticos ${ }^{106}$. Cuidados especiais devem ser adotados em indivíduos idosos, condição em que a farmacocinética e a farmacodinâmica dos medicamentos modificam sua efetividade, tornando a medicação menos tolerada. Essa situação é agravada quando se considera que nas faixas etárias em que a neuralgia do trigêmeo é mais prevalente, outros fármacos habitualmente necessários para o tratamento de afecções concorrentes ou concomitantes podem interagir com 
os antineurálgicos. Yoshimasu e cols. ${ }^{115}$ observaram que $41,6 \%$ dos doentes tratados a longo prazo com carbamazepina, difenil-hidantoína e vitaminas do complexo B mantiveram-se sem dor. Os demais necessitaram tratamento cirúrgico. Segundo Dallessio $^{27}$, em $25 \%$ a $50 \%$ dos doentes ocorre resistência aos antineurálgicos algum tempo após o início do tratamento.

Todos os doentes da presente casuística haviam sido medicados com carbamazepina, 10 com difenilhidantoína, 13 com amitriptilina e 3 com baclofeno. A CGGB foi indicada quando ocorreu intolerância, perda ou ausência da eficácia dos medicamentos antineurálgicos.

Várias classes de fármacos são utilizadas com finalidade antineurálgica. Alguns anticonvulsivantes, miorrelaxantes, psicotrópicos e anestésicos locais são regularmente empregados no tratamento da neuralgia do trigêmeo. Carbamazepina, oxicarbazepina, difenilhidantoína, clonazepam, valproato de sódio, ácido valpróico, gabapentina, baclofeno e mefenezina são os agentes mais utilizados com tal finalidade ${ }^{104,106}$. Amitriptilina, pimozida e outros psicotrópicos são prescritos em casos especiais. Os anestésicos locais, por via intravenosa ou oral são indicados para o controle das crises álgicas intensas ${ }^{104,106}$. A administração dos analgésicos deve ser realizada regularmente, e não apenas quando necessário. Esses cuidados reduzem o sofrimento e a ansiedade dos doentes, a sensibilização das vias nociceptivas e a quantidade de analgésicos necessária para o controle da dor ${ }^{105}$. Cuidados especiais devem ser adotados em indivíduos idosos, condição em que a farmacocinética e a farmacodinâmica dos medicamentos modificam sua efetividade, tornando a medicação menos tolerada. Essa situação é agravada quando se considera que nas faixas etárias em que a neuralgia do trigêmeo é mais prevalente, outros fármacos habitualmente necessários para o tratamento de afecções concorrentes ou concomitantes, podem interagir com os antineurálgicos ${ }^{105,107}$.

Apesar dos grandes avanços na terapêutica medicamentosa, grande número de doentes com neuralgia do trigêmeo necessita tratamento neurocirúrgico para alívio da dor d,27,13,71,81,83,84 $^{\text {. Siegfried }}{ }^{94}$ considera que há indicação de cirurgia quando os antineurálgicos necessitam ser empregados continuadamente. O tratamento deve levar em conta os riscos relativos, os benefícios e os custos das opções analgésicas $^{105}$.

A neuralgia do trigêmeo ocorre, freqüentemente, em indivíduos idosos e, portanto, com maior potencial de risco cirúrgico. O método operatório ideal deve eliminar a dor, produzir mínimo traumatismo às estruturas nervosas, de riscos mínimos, ter baixo índice de recorrência, ser simples, de baixo custo operacional e acessível. Há, entretanto, muitas controvérsias a respeito dos méritos de cada técnica operatória. Algumas referem-se ao modo pelo qual as estruturas trigeminais devam ser lesadas e outras à remoção das hipotéticas etiologias da dor ${ }^{105}$. Entre os métodos ablativos, a rizotomia percutânea por radiofreqüência e a compressão com balão são atualmente os mais empregados ${ }^{24,25,104}$. Entre os métodos que objetivam a remoção das causas, destaca-se a descompressão neurovascular da raiz trigeminal. Os méritos da neurólise do gânglio de Gasser pelo glicerol necessitam ser mais bem avaliados ${ }^{104}$.

A compressão das vias periféricas trigeminais é praticada há algumas décadas e revelou-se, após a introdução de modificações recentes, eficaz e segura. Mullan e Lichtor ${ }^{73}$ fundiram os conceitos de Taarnhfj ${ }^{100}$ e de Shelden ${ }^{93}$ com os preceitos dos procedimentos percutâneos, descrevendo a técnica de CGGB com a finalidade de simplificar as técnicas de compressão até então em uso. O procedimento, que consiste na punção percutânea do forame oval, sob anestesia geral, de curta duração, e na introdução de um balão de Fogarty no gânglio de Gasser, seguida da introdução de $0,7 \mathrm{ml}$ a $1,0 \mathrm{ml}$ de contraste iodado para a distensão do balão, revelou-se simples, rápido e seguro. Ocorreu melhora da dor na maioria de seus 50 doentes tratados. Durante período de seguimento, que variou de 6 meses a 4,5 anos, houve recidiva em $12 \%$ dos casos; estimaram que a taxa de recorrência em cinco anos seria de $20 \%$, portanto, similar à de outros procedimentos em uso. Com aperfeiçoamentos, a técnica passou a ser indicada, também, no tratamento de outras condições, como neuralgia decorrente de esclerose múltipla, neuralgia secundária a processos expansivos e neuralgia atípica da face. Nesses últimos casos, entretanto, os resultados foram menos satisfatórios que os observados em doentes com neuralgia essencial do trigêmeo ${ }^{10,11,18,20,36,68,80,116}$.

Durante a execução do presente trabalho, a punção do forame oval foi realizada com agulhas de biópsia hepática ou agulhas $14 \mathrm{G}$ usadas para o implante de eletrodos epidurais. Inicialmente, foram utilizadas agulhas de Silverman e, durante os últimos 15 procedimentos, as agulhas para implante de eletrodos epidurais, pois as primeiras são calibrosas, o que tornava difícil a punção do forame oval e aumentava o traumatismo no trajeto da punção. Foi selecionado o cateter de Fogarty 4F produzido pela Edwards Laboratory Inc., EUA, porque apresenta diâmetro regular em toda sua extensão e adapta-se à agulha 14G. Em um doente da presente casuística com neuralgia bilateral utilizou-se um cateter de Fogarty 3F, porque não havia disponibilidade de outro equipamento durante a realização do procedimento. Entretanto, a 
melhora induzida foi parcial, havendo persistência de zonas de gatilho e necessidade de intervenção complementar com cateter apropriado que resultou em alívio da sintomatologia. Não houve dificuldades técnicas para a punção do forame oval ou para a insuflação do balão durante a execução dos segundos procedimentos, o que sugere que a CGGB não promove reações cicatriciais marcantes.

Várias técnicas radiológicas foram descritas com a finalidade de possibilitar a localização do forame oval. A incidência axial submento-vértex, que revela a posição do forame oval e do forame espinhoso, apresenta risco para doentes com estenose espinal ou instabilidade da coluna cervical ${ }^{91}$. Nugent e Berry ${ }^{75}$ basearam-se em reparos ósseos, na incidência ânteroposterior e lateral do crânio. Whisler e Hill ${ }^{12}$ e Tator e Rowed $^{102}$ descreveram a incidência oblíqua do crânio para demonstrar o forame oval projetado rostralmente à pirâmide petrosa, medial e anteriormente à borda do processo coronóide da mandíbula e lateralmente à parede lateral do antro do seio maxilar. Radiografias pré-operatórias do crânio na incidência submentovértex para visualização do forame oval podem predizer as dificuldades possíveis para a realização da punção em doentes em que o forame oval é de pequeno diâmetro. Alguns autores recomendam a combinação da incidência submento-vértex, ântero-posterior e late$\mathrm{ral}^{18,42}$. Durante a realização do procedimento, optou-se pela incidência radioscópica de perfil, pois esta possibilita estimar a posição espacial do forame oval e alertar o operador quanto à profundidade da punção.

Na presente casuística, o procedimento foi realizado em regime ambulatorial ou durante internação de até 24 horas, o que tornou reduzido seu custo operacional. Foi realizado sob anestesia geral de curta duração, em ambiente cirúrgico, onde havia possibilidade de realização de manobras de reanimação cardiopulmonar e de ventilação com máscara. Como o tempo médio do procedimento foi curto (15 minutos), a ventilação com máscara foi suficiente; em apenas três doentes foi necessária intubação endotraqueal. A maioria dos autores realiza esse procedimento sob anestesia geral ${ }^{10,16,18,35,68,73}$. Nos 20 primeiros doentes de Abdennebi e Amzar ${ }^{1}$, a cirurgia foi realizada sob neuroleptanalgesia, e nos seus últimos 30 procedimentos, sob anestesia geral. Mullan e Lichtor $^{73}$ recomendam a realização de anestesia geral e intubação endotraqueal, com a finalidade de permitir que a via aérea seja mantida pérvia durante a retroflexão do pescoço, posicionamento necessário para a realização de radiografias na incidência submento-vértex. Esta tática é, também, adotada por outros autores ${ }^{1,10,18,19,36,67,72}$. Esposito e cols. ${ }^{34}$, Fraioli e cols. ${ }^{36}$ e Lobato e cols. ${ }^{66}$ realizaram a CGGB sob neuroleptanalgesia sem intubação endotraqueal e Peragut e cols. ${ }^{80}$, sob anestesia geral de curta duração sem intubação endotraqueal. Em nosso meio, Corrêa e Teixeira ${ }^{25}$ empregaram anestesia geral de curta duração, sem intubação endotraqueal em 79\% de seus casos. Em 17\% (27 de 158) dos doentes de Corrêa e Teixeira $^{24}$, foi realizado bloqueio do gânglio de Gasser com $0,2 \mathrm{ml} \mathrm{a} 0,3 \mathrm{ml}$ de hidroclorido de lidocaína. Esse procedimento anestésico, apesar de dispensar anestesia geral, bloqueia a ocorrência de bradicardia que, segundo Mullan e Lichtor ${ }^{73}$, é reação reflexa que se manifesta normalmente quando o nervo é tocado pela agulha ou sofre compressão pelo balão, constituindo parâmetro que assegura que a compressão foi eficaz. A bradicardia pode ser aliviada com o esvaziamento do balão ou com uso de atropina. Belber e Rak ${ }^{10}$ e Lobato e cols. ${ }^{66}$ indicam rotineiramente atropina intravenosa para prevenir bradicardia. Brown e Preul ${ }^{18}$ e Brown e Gouda ${ }^{17}$ usam marca-passo externo, pois a bradicardia pode ser muito mais precoce e, possivelmente, não controlada com o uso de drogas administradas habitualmente.

No presente estudo, bradicardia e hipotensão arterial foram observadas em todos os doentes durante a punção do forame oval e quando a agulha entrou em contato com o ramo mandibular, tornando-se mais acentuadas durante a distensão do balão. Em ambas as condições, cederam prontamente após o esvaziamento do balão e não impossibilitaram a conclusão do procedimento; ao se manifestarem, foram realizadas distensões mais alentecidas do balão até alcançar o volume máximo comportado pelo cavum de Meckel ou até atingir o volume de $1 \mathrm{ml}$. Outros autores também enfatizaram os efeitos neurovegetativos resultantes dos estímulos trigeminais em animais e seres humanos durante a manipulação ou estimulação do nervo trigêmeo, gânglio de Gasser ou trato espinal do nervo trigêmeo ${ }^{19,44,50,62,69,97,109}$. Mullan e Lichtor ${ }^{73}$ referem que em algum momento durante a penetração da agulha no forame oval e durante a insuflação do balão ocorre, comumente, bradicardia significante, mas de curta duração e alertam para a necessidade do uso de atropina para preveni-la, apesar de esse fenômeno constituir confirmação fisiológica da penetração do forame oval e da compressão do gânglio de Gasser. Observou-se que, após compressão inicial, não mais ocorre bradicardia durante compressões ulteriores ${ }^{73}$. Brown e Preul ${ }^{19}$ realizaram 23 CGGB e observaram que ocorreu bradicardia e hipotensão arterial com valor estatístico significante $(\mathrm{p}<0,0002)$ quando a agulha penetrava no forame oval e durante $o$ avanço do cateter e distensão do balão no interior do cavum de Meckel. Em $70 \%$ dos procedimentos, a freqüência cardíaca reduziu-se abruptamente para 60 batimentos por minuto ou menos, sendo o valor médio de redução, 38\%; a pressão arterial média reduziu-se transitoriamente em $31 \%$ do seu valor inicial em $55 \%$ dos doentes. Outros autores, entretanto, notaram que ocorreu hipertensão arterial e, às vezes, taquicardia durante a punção do 
gânglio de Gasser. Dominguez e cols. ${ }^{33}$ analisaram as características das reações pressóricas e do ritmo cardíaco induzidas pela CBGG durante o tratamento da neuralgia essencial do nervo trigêmeo em 42 doentes. Os primeiros 22 doentes (grupo I) foram submetidos à operação sob anestesia geral de curta duração sem intubação endotraqueal. Dez doentes (grupo II) foram operados sob anestesia geral, intubação endotraqueal, ventilação mecânica e tratados com elevadas doses de hipnóticos e analgésicos. Outros dez doentes (grupo III) foram operados sob bloqueio anestésico local do cavum de Meckel com $1 \mathrm{ml}$ de lidocaína a 2\% e anestesia geral e intubação endotraqueal. A punção do forame oval promoveu bradicardia na maioria dos doentes dos grupos II e III, mas só quatro (18\%) doentes do grupo I apresentaram esta anormalidade.

A compressão do gânglio promoveu acentuada taquicardia em todos os doentes dos grupos I e II; cerca de um terço desses doentes apresentou extrasístoles. Os doentes do grupo III tratados com bloqueio do gânglio de Gasser com anestésico local antes da compressão não apresentaram taquicardia ou extra-sístoles. A punção do forame oval promoveu acentuado aumento da pressão sistólica em todos os doentes. A compressão ganglionar elevou ainda mais a pressão arterial, exceto nos doentes do grupo III, que tinham sido tratados com bloqueio do gânglio de Gasser com anestésico local.

Esses autores afirmaram que a elevação da pressão arterial promovida pela punção do forame oval e pela compressão do gânglio de Gasser é resultado da elevação transitória dos níveis séricos de adrenalina e noradrenalina e dura poucos minutos. Concluem que a reação simpático-adrenal induzida pela compressão do gânglio trigeminal não é modificada pela profundidade da anestesia geral, e que o bloqueio anestésico do gânglio de Gasser previne a ocorrência da hipertensão arterial e da taquicardia.

Kehler e cols. ${ }^{58}$ relataram reação hipertensiva durante a realização da rizotomia percutânea trigeminal por radiofreqüência; a elevação da pressão arterial foi de, pelo menos, $25 \%$ durante a coagulação em $76 \%$ de 21 procedimentos. Sweet e cols. ${ }^{99}$ também descreveram elevação da pressão arterial durante a coagulação da raiz trigeminal. A reação de bradicardia e hipotensão arterial durante a CBGG difere da reação hemodinâmica, caracterizada por taquicardia e hipertensão arterial, durante a rizotomia por radiofreqüência, talvez, porque diferentes fibras são lesadas em cada um destes procedimentos; a CGGB lesa preferencialmente fibras grossas mielinizadas e a rizotomia por radiofreqüência, as fibras mielinizadas finas seguidas das fibras nãomielinizadas ${ }^{17,19,98}$. Os estímulos veiculados pelo sistema sensitivo trigeminal exercem grande influência na função cardiovascular. A ação cardioinibitória do nervo trigêmeo foi primeiro descrita por Aschner ${ }^{6}$, como reflexo oculocardíaco. Dellow e Morgan ${ }^{32}$ descreveram reação vasodepressora e bradicardia à estimulação elétrica da polpa dentária de gatos; estímulos de $10 \mathrm{~Hz}$ a $60 \mathrm{~Hz}$ promoveram redução de $30 \mathrm{mmHg}$, em média, na pressão arterial. A intensidade da reação dependeu da profundidade da anestesia e da intensidade e freqüência dos estímulos e foi, freqüentemente, seguida por fase de hipertensão arterial nos animais sob anestesia superficial. Kumada e cols. ${ }^{62}$ descreveram resposta depressora trigeminal em ratos após a estimulação elétrica a baixa freqüência $(5 \mathrm{~Hz}$ a $10 \mathrm{~Hz}$ e $10 \mathrm{uA}$ a $1.000 \mathrm{uA}$ ) do núcleo do trato espinal ou dos ramos periféricos do nervo trigêmeo, caracterizada por bradicardia, hipotensão arterial, apnéia e hipermotilidade gástrica. Ocorreu maior reação hipotensora com a estimulação do trato espinal do trigêmeo. Essas reações diferem das do reflexo barorreceptor carotídeo porque não são abolidos após a lesão no núcleo do trato solitário.

O fato de a bradicardia e a hipotensão arterial poderem promover hipoperfusão e infarto cerebral ou miocárdico implica necessidade de monitorização cardiorrespiratória durante a execução da CGGB. Esse cuidado é especialmente indicado em doentes com mais de 70 anos de idade, condição em que há maior instabilidade cardiovascular. A bradicardia pode ser aliviada com o esvaziamento do balão ou com uso de atropina. Na presente casuística, foi administrada atropina nos doentes em que se constatou bradicardia acentuada. $\mathrm{O}$ bloqueio colinérgico reduz, mas não previne, a bradicardia ou a hipotensão arterial, pois durante a compressão ganglionar, a resposta inclui a ativação de fibras vagais cardioinibitórias e a inibição da vasoconstrição adrenérgica ${ }^{10}$. Brown e Gouda ${ }^{17}$ acionam o marca-passo externo quando a freqüência cardíaca atinge 45 batimentos por minuto, fenômeno que ocorreu em dois terços de seus doentes. No presente estudo, a administração de atropina foi necessária apenas em duas oportunidades e o marca-passo externo não foi necessário em nenhuma ocasião.

A estimulação mecânica nóxica ou térmica da face também promove bradicardia, hipotensão arterial e inibição da atividade nervosa simpático-adrenal. Segundo Terui e cols. ${ }^{109}$, essa reação é mediada pelas fibras aferentes primárias A-delta, isoladamente, ou associadamente às fibras $\mathrm{C}$. Kumada e cols. ${ }^{62}$, com finalidade de determinar se a reação hipotensora trigeminal seria simplesmente reacional à dor, avaliaram ratos submetidos à transecção mediocolicular. Concluíram que o cérebro não é parte imprescindível no mecanismo desse reflexo; as vias trigeminais nociceptivas poderiam estar conectadas com o sistema nervoso neurovegetativo da medula espinal ou do tronco encefálico. Ruggiero e cols. ${ }^{86}$ demonstraram 
haver projeções do núcleo espinal do nervo trigêmeo para toda extensão da medula espinal em ratos. Menétrey e Basbaum ${ }^{69}$ demonstraram, em ratos, que há maciças projeções de neurônios espinais e trigeminais, especialmente dos núcleos paratrigeminais, para o núcleo solitário. Estímulos aferentes oriundos da face poderiam ser transmitidos para o núcleo do trato solitário via trato solitário trigêmino-espinal. Parte desse estímulo é nociceptivo e gerado por estímulos dolorosos reflexos somatoviscerais e visceroviscerais. Outros reflexos trigeminais apresentam características diferentes; o reflexo oculocefálico é associado com bradicardia, mas não com hipotensão arterial $^{6}$; o reflexo de afogamento e o reflexo nasofaríngeo (estimulação dolorosa da mucosa olfatória) causam aumento da resistência vascular periférica e hipertensão arterial $^{62}$.

Após compressão satisfatória, ocorre, freqüentemente, hiperemia conjuntival ipsilateral, talvez devido ao comprometimento temporário da função neurovegetativa $^{66}$. Esse fenômeno foi observado em todos os doentes da presente casuística e parece sinalizar ocorrência de compressão satisfatória do gânglio de Gasser.

Ocorreu alívio da dor, imediatamente após a realização do procedimento, em $37(90,26 \%)$ hemifaces, melhora em $2(4,87 \%)$ e ausência de melhora em 2 $(4,87 \%)$. Após a segunda compressão, ocorreu alívio total e imediato da dor em todos os doentes. Esses resultados são superiores aos descritos em nosso meio por Corrêa e Teixeira ${ }^{25}$, que trataram 189 doentes e observaram alívio imediato da dor em $150(79,4 \%)$ doentes. Outros autores observaram que há alívio imediato da dor em $64 \%$ a $100 \%$ dos doentes submetidos a este procedimento. Bricolo e Dalle ${ }^{16}$ descreveram alívio imediato da dor em $100 \%$ de seus doentes; Mullan e Lichtor ${ }^{73}$, em 98\%; Fraioli e cols. ${ }^{36}$, em 98\%; Esposito e cols. ${ }^{34}$, em 64\%; Fiume e cols..$^{35}$, em $100 \%$; Belber e Rak ${ }^{10}$, em 100\%; Meglio e cols. ${ }^{68}$, em 100\%; Brown e Preul ${ }^{18}$, em 100\%; Fraioli e cols. ${ }^{36}$, em 90\%; Lichtor e Mullan ${ }^{65}$, em 100\%; Lobato e cols. ${ }^{66}$, em 100\%; Abdennebi e Amzar ${ }^{1}$, em 92\%; e Peragut e cols. $^{80}$, em $97,5 \%$.

Poucas foram as complicações durante o procedimento na presente casuística. Foram representadas por hipoestesia facial, paresia da musculatura mastigatória, anormalidades da motilidade ocular e erupções pelo vírus do herpes simples. Ocorreu hipoestesia discreta da hemiface em $68,4 \%$ dos casos, hipoestesia moderada em $29,2 \%$ e ausência de anormalidades sensitivas em apenas um doente $(2,4 \%)$ após a primeira cirurgia. A hipoestesia facial resultante da segunda compressão não foi adicionalmente mais desconfortante do que a da primeira e foi bem tolerada pelos doentes. Somente dois doentes da presente casuística, submetidos à compressão durando 120 segundos na segunda cirurgia, apresentaram disestesias desagradáveis, que foram controladas com carbamazepina. Geralmente, durante os primeiros dias que se seguem ao procedimento, os doentes percebem o desconforto e a ocorrência de hipoestesia. Ao final do primeiro mês, a dormência, geralmente, reduz-se e, aos seis meses, desaparece na maioria dos doentes. Corrêa e Teixeira ${ }^{24}$ observaram desaparecimento das anormalidades sensitivas durante período de tempo de duas semanas a três meses, exceto em $15 \%$ de seus doentes. $\mathrm{Na}$ presente casuística, a melhora da hipoestesia facial não foi acompanhada de recidiva da dor. Não há, portanto, relação entre a intensidade da hipoestesia e a ocorrência e a duração do alívio da dor. A paresia da musculatura mastigatória foi referida por dez $(24,4 \%)$ doentes após a primeira cirurgia e em todos os doentes após a segunda operação; nestes, somente em três, foi incômoda. Em nenhum doente foi observada paresia da musculatura mastigatória na avaliação dos seis meses. Apenas dois doentes referiram diplopia transitória que desapareceu após 30 dias de seguimento. Déficit da musculatura mastigatória e diplopia foram mais freqüentes quando o balão adquiriu a forma em ampulheta e após a segunda cirurgia. A erupção cutânea facial pelo vírus do herpes simples ocorreu em quatro $(9,8 \%)$ doentes durante as primeiras 48 horas após a cirurgia. Hematoma facial discreto, ipsilateral à punção, ocorreu em três $(7,3 \%)$ doentes e desapareceu em menos de duas semanas. Durante o acompanhamento dos doentes submetidos à CGGB, que durou três anos e seis meses, Fraioli e cols. ${ }^{36}$ observaram que a sensibilidade da face tornou-se normal ou discretamente comprometida em 104 doentes, houve moderado comprometimento em 30\% dos casos e déficit intenso em quatro. Déficit da musculatura mastigatória induzida pela compressão ocorreu em um terço de seus doentes e foi mais comum quando havia história de cirurgias prévias; teve duração média de dois meses. Um de seus doentes apresentou déficit moderado da musculatura mastigatória, que persistiu durante dois meses, um apresentou déficit funcional permanente do nervo abducente e dois, paresia transitória desse nervo. $\mathrm{Na}$ casuística de Corrêa e Teixeira ${ }^{24}$, ocorreu erupção pelo vírus do herpes simples ipsolateral à operação em seis doentes, meningite bacteriana em dois, hemorragia facial em sete e rotura do balão em 16 ocasiões.

Mullan e Lichtor $^{73}$ atribuem o alívio da dor à lesão anatômica ou funcional das estruturas trigeminais devido à isquemia resultante da compressão. Brown e cols. ${ }^{20}$ realizaram a CGGB em ratos e notaram que ocorreu edema, fragmentação axonal e degeneração acentuada das fibras da raiz sensitiva, e degeneração transganglionar no complexo nuclear trigeminal no tronco encefálico, que recebe aferências das fibras grossas mielinizadas, sete dias após a compressão. 
Concluíram que o alívio da dor deveria ser decorrente da lesão das fibras grossas e mielinizadas, e não das células ganglionares. As fibras do ramo oftálmico sofrem degeneração menos intensa que as de outros nervos, devido, provavelmente, ao fato de o balão comprimir mais intensamente o ramo mandibular, localizado lateralmente no forame oval; não ocorreu degeneração das células ganglionares de pequenas dimensões ou das fibras de fino calibre, o que justifica a preservação da sensibilidade corneana e do reflexo de piscamento, mediados pelas fibras finas do ramo oftálmico. Esses achados sugerem que a CGGB seja procedimento percutâneo ablativo apropriado para o tratamento da neuralgia do ramo oftálmico. Urculo e cols. ${ }^{11}$ realizaram CGGB em dez cadáveres adultos frescos e observaram que, quando o balão foi inflado até sua capacidade máxima $(0,75 \mathrm{ml} \mathrm{a} 1 \mathrm{ml})$, ocorreu abaulamento dural da parede lateral do seio cavernoso até o poro trigeminal, correspondendo à superfície de $15 \mathrm{~mm} \times 10 \mathrm{~mm}$, e que não ocorreram roturas ou fissuras na dura-máter ou nas fibras do nervo trigêmeo. Após o esvaziamento do balão, a dura-máter do cavum de Meckel tornou-se flácida, indicando que a "microcompressão ganglionar" induz "descompressão da duramáter do gânglio e da raiz trigeminal".

Os achados dependeram da localização e do volume do balão; alterações anatômicas significantes ocorreram quando a extremidade do cateter localizou-se no poro trigeminal, em um ponto situado de $15 \mathrm{~mm}$ a $20 \mathrm{~mm}$ proximalmente ao forame oval e quando o balão foi inflado com $0,75 \mathrm{ml} \mathrm{a} 1 \mathrm{ml}$ de contraste. Quando o balão foi inflado no ângulo pontocerebelar, estando a extremidade do cateter situada proximalmente em relação ao poro trigeminal, não ocorreram os mesmos efeitos. Concluíram que o aspecto técnico mais importante do procedimento foi a localização da extremidade do cateter em relação ao poro trigeminal; o balão completamente inflado deveria adquirir a forma de pêra, na incidência radiográfica lateral, para produzir efeitos mecânicos apropriados nos elementos neurais e na dura-máter. Outro aspecto importante foi a pressão de compressão; o efeito foi pequeno quando as pressões situaram-se abaixo de $600 \mathrm{mmHg}$. A pressão exercida foi diretamente relacionada à resistência de estiramento da dura-máter.

Foi induzida a forma de ampulheta ao balão em $48,8 \%$ dos primeiros procedimentos na presente casuística, a forma em pêra em $43,9 \%$ e, a forma oval, em 7,3\%. Mullan e Lichtor ${ }^{73}$ descreveram quatro formas de balão: a forma que consideraram satisfatória foi a "em pêra", que ocorre quando o balão está no interior do cavum de Meckel; a forma denominada "não em pêra", que ocorre quando o cavum de Meckel é volumoso, relaciona-se com a falha do procedimento; a "irregular", ou seja, de conformação bizarra, que se deve a cicatrizes no cavum de Meckel devido a prévias injeções de álcool no seu interior ou a outras anormalidades, associa-se à tendência de migração do balão para a fossa posterior; a forma em "ampulheta" é devida à protrusão da extremidade distal do balão para a fossa posterior, através do poro trigeminal. Segundo Hakanson ${ }^{45}$, o diâmetro vertical médio do poro trigeminal, na projeção lateral, é de 2,8 $\mathrm{mm}$. Quanto maior o balão, maior a tendência de deslocamento para a fossa posterior; volumes adicionais de contraste não aumentam a pressão intraluminal, mas promovem maior migração em direção à fossa posterior. Nesses casos, para haver compressão satisfatória, o cateter deve ser recuado em alguns milímetros.

Ocorreu tendência de os doentes, nos quais a forma em ampulheta foi induzida, apresentarem maior freqüência de alívio da dor, e naqueles em que a forma em pêra foi induzida, de apresentarem maior magnitude de déficit motor mastigatório e sensitivo da face. Esse achado sugere que a relação benefício-déficit é favorável à forma em ampulheta. Em três doentes, a forma induzida foi a oval, que resultou em alívio da dor em apenas um doente que apresentou discreta hipoestesia facial e ausência de déficit funcional da musculatura mastigatória. A correlação entre a forma do balão e os resultados foi avaliada por poucos autores. Lobato e cols. ${ }^{66}$ observaram que a forma oval associase a menor grau de déficit sensitivo. Contrariando o observado na presente casuística, notaram alívio da dor em doente, por eles operado, em que a pressão no balão com forma oval foi de $700 \mathrm{mmHg}$. Esses autores, entretanto, ressalvam que esta forma está associada a maus resultados porque é induzida quando o balão ou está mal localizado ou o volume de injetado é insatisfatório. Consideram, ainda, ser a forma em pêra induzida com pressões médias de $1.150 \mathrm{mmHg}$ a ideal e que a forma em ampulheta induzida com pressões de 1.700 $\mathrm{mmHg}$ relaciona-se a maior grau de hipoestesia facial, dados que estão em desacordo com o observado na presente casuística. Possíveis variações na pressão do balão justificariam tais discrepâncias. Conclui-se, portanto, que tanto a forma em pêra como em ampulheta são relacionadas à melhora da dor. $\mathrm{O}$ mesmo não ocorre quando a forma oval é induzida, porque o volume de insuflação é insuficiente para preencher o cavum de Meckel, ou o balão está localizado proximalmente ao poro trigeminal ou no espaço subtemporal.

A compressão do gânglio de Gasser foi realizada durante 60 segundos na primeira intervenção em todos os casos, e durante 120 segundos na segunda. O prolongamento do tempo da compressão no segundo procedimento foi fundamentado na expectativa de que quanto mais prolongada fosse a ação do agente físico mecânico, mais expressivas seriam as anormalidades biodinâmicas induzidas nas estruturas trigeminais ${ }^{37}$. A segunda compressão, realizada com duração de 120 
segundos, resultou em hipoestesia facial mais acentuada, mas não mais desconfortável; nenhum dos nove doentes reoperados apresentou anestesia dolorosa na face. Isso permite inferir que, em alguns doentes, há necessidade de período de compressão superior a 60 segundos e, talvez, maior volume de distensão do balão, para a indução da melhora da dor. Mullan e Lichtor $^{73}$, no seu trabalho pioneiro, descreveram os resultados observados em 22 doentes submetidos à compressão com duração variando de três a dez minutos e, mais freqüentemente, de cinco a sete minutos; um doente com neuralgia decorrente de esclerose múltipla foi submetido à compressão durando 30 segundos. Observaram que a compressão prolongada acarretou maior freqüência de complicações, especialmente, hipalgesia ou anestesia. Concluíram que após a aquisição da forma em pêra, a compressão deve ser mantida durante um a dois minutos. Lichtor e Mullan ${ }^{65}$ submeteram 100 doentes com neuralgia trigeminal à técnica de CGGB; os primeiros foram submetidos à compressão com duração variando de cinco a sete minutos; após o sexagésimo procedimento, a duração da compressão foi fixada em um minuto, pois, com esse período de tempo havia menor ocorrência de disestesias e hiperestesias. Meglio e $\mathrm{Cioni}^{67}$ relataram os resultados do tratamento de 33 doentes e concluíram que o tempo apropriado de compressão deveria variar de quatro a seis minutos. Fraioli e cols. ${ }^{37}$ realizaram compressão durante quatro minutos e trinta segundos. Meglio e Cioni ${ }^{67}$ realizaram compressão durando um a três minutos em 21 doentes, quatro a seis minutos em 47 doentes e sete a dez minutos em 6 doentes. Fraioli e cols. ${ }^{37}$, analisando os resultados observados em 159 doentes submetidos à CGGB durante três a sete minutos e, ulteriormente, durante um a dois minutos, concluíram que estes últimos períodos de tempo deveriam ser os mais adequados para promover alívio da dor. Com esta técnica, induziram hipoestesia facial em mais de um ramo trigeminal; esta reduziu-se, acentuadamente, dias ou meses após, e associou-se à taxa de recorrência aceitável. A compressão foi repetida com duração de tempo mais prolongado em 12 doentes que apresentaram recidiva, ocorrendo alívio da dor somente em 4 deles. O déficit sensitivo foi proporcional à duração da compressão. A duração da compressão necessária para alívio da dor está relacionada a fatores constitucionais e anatômicos dependentes da forma e volume do cavum de Meckel e do poro trigeminal. Quando houver necessidade da segunda operação, os riscos e benefícios devem ser considerados. A compressão prolongada gerou hipoestesia da face que se manteve durante seis meses, em seis doentes e, durante 12 meses, em outros três. Doentes avaliados aos 18 meses não a apresentavam; dois doentes descreveram disestesias faciais. Conclui-se que quanto mais intensa a desaferentação, maior a possibilidade de disestesias. Não houve relação entre a intensidade da desaferentação e o alívio da dor nos doentes da presente casuística. Isso implica que o desaparecimento da hipoestesia não promove, necessariamente, recidiva da dor, apesar de nenhum doente, em que a reoperação foi indicada, ter apresentado hipoestesia facial pré-operatória.

Os volumes de distensão do balão variaram de $0,7 \mathrm{ml}$ a $1 \mathrm{ml}$ durante a primeira e segunda compressões. Foi de $0,7 \mathrm{ml} \mathrm{em} 4(9,7 \%)$ procedimentos; $0,8 \mathrm{ml}$ em 13 (31,7\%); $0,9 \mathrm{ml} \mathrm{em} 13$ (31,7\%) e $1 \mathrm{ml} \mathrm{em} 11$ (26,9\%). O volume de contraste necessário para distender o balão está intimamente relacionado com o volume do cavum de Meckel; a forma do balão depende do volume do cavum de Meckel e do diâmetro livre do poro trigeminal. Sabe-se que a capacidade do balão é de $0,75 \mathrm{ml}$, mas há possibilidade de injeção de até $1 \mathrm{ml}$ sem rotura, quando o cavum de Meckel não apresenta cicatrizes. Segundo Mullan e Lichtor ${ }^{73}$, o cavum de Meckel varia quanto ao tamanho; o balão deve ser distendido até assumir a forma de pêra, indicando que se iniciou sua protrusão para a fossa posterior, o que, usualmente, requer injeção de $0,5 \mathrm{ml} \mathrm{a} 1 \mathrm{ml}$ (média de $0,7 \mathrm{ml}$ ) de contraste. Estudos sobre cisternografia trigeminal durante a realização de rizotomia com glicerol determinaram que o volume médio da cisterna varia de $0,1 \mathrm{ml}$ a $0,5 \mathrm{ml}$ (média de $0,24 \mathrm{ml})^{45,57}$. Na presente casuística, os doentes submetidos à compressão com volumes menores apresentaram mais disfunção da musculatura mastigatória e menor freqüência de hipoestesia da face, mas não interferiu nos resultados frente à melhora ou o alívio da dor.

A correlação entre tempo de compressão e volume do balão foi avaliada por alguns autores. Bricolo e Dalle ${ }^{16}$ recomendaram tempo médio de compressão de seis minutos e volume de $0,6 \mathrm{ml}$; Mullan e Lichtor $^{73}$, tempo de um minuto e trinta segundos e volume de $0,75 \mathrm{ml}$; Esposito e cols. ${ }^{34}$, tempo de cinco minutos e volume de $0,6 \mathrm{ml}$; Fiume e cols. ${ }^{35}$, tempo de seis minutos e trinta segundos e volume de $0,85 \mathrm{ml}$; Belber e Rak ${ }^{10}$, tempo de quatro a dez minutos e volume de $0,5 \mathrm{ml}$ a $1 \mathrm{ml}$ (tempo médio de sete minutos e volume médio de $0,75 \mathrm{ml}$ ); Meglio e cols. ${ }^{68}$, tempo de cinco minutos e volume de $0,75 \mathrm{ml}$; Brown e Preul ${ }^{19}$, tempo de compressão de um a três minutos e volume de $0,75 \mathrm{ml} \mathrm{a} 1 \mathrm{ml}$; Brown e Preul ${ }^{18}$, tempo de um minuto e trinta segundos e volume de 0,85 $\mathrm{ml}$; Lobato e cols. ${ }^{66}$, volume de $0,5 \mathrm{ml}$ a $1 \mathrm{ml}$ (média de 0,8 $\mathrm{ml}$ ) e tempo de um a três minutos; Peragut e cols. ${ }^{80}$, tempo de compressão de um a três minutos (média de um minuto) e volume de $0,75 \mathrm{ml}$ a $1 \mathrm{ml}$; Abdennebi e Amzar ${ }^{1}$, tempo de compressão de sete a nove minutos (média de 
oito), e volume de $0,5 \mathrm{ml}$; Corrêa e Teixeira ${ }^{24}$, tempo de 60 segundos e volume de $0,65 \mathrm{ml} \mathrm{a} 1 \mathrm{ml}$.

$\mathrm{Na}$ presente casuística, foi considerado o tratamento como falho quando não houve melhora da dor após a realização do procedimento em condições adequadas, ou seja, dificuldade para punção do forame oval e para insuflação do balão. Foram consideradas recidivas quando após o alívio total ou melhora da dor, ocorreu recorrência do quadro álgico. Ocorreram quatro recidivas durante os primeiros 24 meses, uma aos 36 e outra aos 42 meses. Esse fato sugere que as recidivas são mais freqüentes durante os dois primeiros anos de acompanhamento pósoperatório, mas podem ocorrer, tardiamente, após o terceiro ano decorrido da cirurgia. A taxa de recidiva da neuralgia do trigêmeo na presente casuística foi de $15 \%$ durante período de acompanhamento de até 48 meses, achado que concorda com a de outros autores que relatam taxa de recidiva variando de $4 \%$ a $55 \%$ (média de 24\%), na dependência do período de tempo de acompanhamento ${ }^{11,35,37,66,68,73}$. Na casuística de Bricolo e Dalle ${ }^{16}$, a taxa de recorrência foi de $20 \%$ em 19 meses; na de Mullan e Lichtor ${ }^{73}$, 15\% em 72 meses; na de Fraioli e cols. ${ }^{37}, 4 \%$ em 8 meses; na de Fiume e cols. ${ }^{35}, 35 \%$ em 12 meses; na de Belber e Rak ${ }^{10}, 24 \%$ em 84 meses; na de Meglio e cols. ${ }^{68}, 55 \%$ em 36 meses; na de Brown e Preul ${ }^{19}, 14 \%$ em 53 meses; na de Abdennebi e Amzar ${ }^{1}, 14 \%$ em 30 meses; na de Lichtor e Mullan ${ }^{65}, 28 \%$ em dez anos; na de Lobato e cols. ${ }^{66}$, $9,7 \%$ entre 10 e 35 meses; e, na de Peragut e cols. ${ }^{80}$, $20,5 \%$ em 60 meses. Mullan e Lichtor ${ }^{73}$ operaram 50 doentes e os acompanharam durante 6 a 54 meses; observaram recorrência de $12 \%$; estimaram que a taxa de recidiva da neuralgia em cinco anos deveria ser de $20 \%$, portanto similar ao período de tempo médio de recidiva da dor após a execução de outros procedimentos percutâneos existentes. Belber e Rak ${ }^{10}$ submeteram 25 doentes a 33 CGGB e os acompanharam durante período de seis meses a sete anos; observaram ter ocorrido cura de longa duração em 25 (76\%) doentes e recorrência em 8 (24\%). Em nosso meio, Corrêa e Teixeira ${ }^{24}$ trataram 189 doentes com 227 CGGB; o procedimento foi realizado uma vez em 150 $(79,4 \%)$ doentes, sendo repetido em $18(9,5 \%)$ doentes devido a problemas técnicos durante a primeira cirurgia e, em 21 (11,1\%), devido à recidiva da dor; três dessas recidivas ocorreram durante os primeiros dois anos; cinco, em três anos; seis, em quatro anos; e sete, em cinco anos.

Meglio e Cioni ${ }^{67}$ compararam os resultados observados em 33 doentes tratados pela CGGB com os de 74 doentes tratados com rizotomia percutânea por radiofreqüência. Ocorreu alívio imediato da dor em $93,2 \%$ dos doentes tratados com CGGB e em $81,8 \%$ dos doentes tratados com radiofreqüência. Dois anos após a cirurgia, houve recorrência da dor em $56 \%$ dos doentes submetidos à CGGB e em $42 \%$ dos doentes submetidos à rizotomia por radiofreqüência. $\mathrm{O}$ tempo médio de recorrência foi de 6 meses após a CGGB e de 18 meses após a rizotomia por radiofreqüência. Disestesias acentuadas ocorreram em $24 \%$ dos doentes após a rizotomia por radiofreqüência e em $6,7 \%$ dos doentes após a CGGB; paresia da musculatura mastigatória foi comum após a CGGB, mas foi incapacitante em apenas um deles. Concluíram que a CGGB apresenta a vantagem da simplicidade e poucos efeitos adversos, e que a dor recorrente, deve ser tratada com a repetição do procedimento a não ser quando localizada no ramo mandibular, situação em que a rizotomia por radiofreqüência torna-se mais apropriada.

Taha e Tew Jr. ${ }^{101}$ analisaram os resultados, a recorrência, a ocorrência de hipoestesia, disestesias e anestesia da córnea, ceratite, déficit motor e da função de nervos cranianos, hemorragias ou infartos intracranianos, morbidade e mortalidade perioperatória de 500 doentes submetidos à rizotomia por radiofreqüência entre 1981 e 1986, em relação aos dados da literatura sobre o mesmo procedimento (6.205 doentes) e os da rizotomia com glicerol (1.217 doentes), rizotomia por CGGB (759 doentes), descompressão neurovascular (1.417 doentes) e rizotomia trigeminal parcial (250 doentes). A descompressão neurovascular apresentou a mais elevada taxa de impossibilidade de execução; a rizotomia por radiofreqüência e a descompressão neurovascular apresentaram as mais altas taxas de alívio inicial da dor e as mais baixas taxas de recorrência; a rizotomia com glicerol apresentou a mais alta taxa de recorrência; a rizotomia por CGGB e a descompressão neurovascular apresentaram as mais baixas taxas de anestesia de córnea e de ceratite; a descompressão neurovascular apresentou a mais baixa taxa de dormência facial e de disestesias e a taxa mais elevada de disfunção permanente de nervos cranianos, hemorragias ou infartos intracranianos e outras complicações.

Os custos do procedimento também são favoráveis à $\mathrm{CGGB}$, pois pode ser realizada ambulatorialmente $\mathrm{e}$ com equipamentos de baixo custo, excluindo-se, obviamente, os aparelhos de imagem.

\section{Conclusões}

1. A compressão do gânglio de Gasser com balão é método terapêutico cirúrgico simples, seguro, de fácil execução, baixo custo operacional e eficaz no tratamento da neuralgia essencial do nervo trigêmeo. 
2. Tempo de compressão durando 60 segundos foi satisfatório para aliviar a dor na maioria dos doentes; compressão durando 120 segundos parece ser mais eficaz, mas está associada a maior número de complicações.

3. A indução da forma do balão em pêra ou ampulheta associou-se à melhora da dor; a forma oval proporcionou resultados insatisfatórios.

4. Houve tendência de a aquisição da forma em pêra causar anormalidades motoras e sensitivas mais intensas e menor freqüência de melhora da dor que a da forma em ampulheta.

5. Menor volume de enchimento do balão associou-se a maior déficit da função da musculatura mastigatória.

6. Não houve relação entre o grau de déficit sensitivo induzido e a melhora da dor.

\section{Referências}

1. ABDENNEBI B, AMZAR Y: Traitement de la névralgie trigéminal essentielle par compression gassérienne par ballonet (50 cas). Neurochirurgie 37:115-8, 1991.

2. ALAJOUANINE T, THUREL R: La névralgie faciale. Importance du stimulus et de la zone d'exitation déductions thérapeutiques et pathogénique. Nouv Presse Med 42:345-8, 1934.

3. ALVISI C, BORROMEI A: Varie modalità stiopatogenetiche della cosidetta nevralgia essenciale del nervo trigemio. Minerva Med 58:64-8, 1967.

4. ARNOULD G, LEPOIRE J, TRIDON P, LAXENAIRE, $M$ : Les neurinomes du trijumeau. Particularités cliniques et radiologiques. Rev Neurol (Paris) 104:302-8, 1961.

5. ARSENI C, DUMITRESCU L, CONSTANTINESCU A: Neurinomes of the trigeminal nerve. Surg Neurol 4:497-503, 1975 .

6. ASCHNER B: Uber einen bisher noch nicht beschriebenen reflex vom auge auf kreislauf und atmung. Verschwinden des radialispulses bei druck auf das auge. Wien Klin Wochenschr 21:1529-30, 1908.

7. AULD AW, BUERMANN A, GABLES A: Trigeminal neuralgia in six members of one generation. Arch Neurol 13:194-8, 1965.

8. BARRAQUER-BORDAS L: Sobre la herencia y etiopatogenia del tic doloroso trigeminal. Arq Neuropsiquiatr (São Paulo) 7:241-63, 1949.

9. BEAVER DL: Electron microscopy of the Gasserian ganglion in trigeminal neuralgia. J Neurosurg 26(suppl.1):138-50, 1967.

10. BELBER CJ, RAK RA: Balloon compression rhizolysis in the surgical management of trigeminal neuralgia. Neurosurgery 20:908-13, 1987.

11. BENNETT MH, JANNETTA PJ: Evoked potentiales in trigeminal neuralgia. Neurosurgery 13:242-7, 1983.

12. BENNETT MH, JANNETTA PJ: Trigeminal evoked potential in humans. Eletroencephalogr Clin Neurophysiol 48:517-26, 1980.
13. BLOM S: Tic doloureux treated with a new anticonvulsant. Experiences with G-32883. Arch Neurol 9:285-90, 1963.

14. BRAGA FM, BONATELLI AP, SURIANO I, CANTERAS M: Familial trigeminal neuralgia. Surg Neurol 26:4058, 1986.

15. BRAY PF, CARTER S, TAVERAS JM: Brain stem tumors in children. Neurology (Minneap) 8:1-7,1958.

16. BRICOLO A, DALLE OG: Percutaneous microcompression of the Gasserian ganglion for trigeminal neuralgia: preliminary results. Acta Neurochir (Wien) 69:102, 1983.

17. BROWN JA, GOUDA JJ: Percutaneous balloon compression of the trigeminal nerve. In Brown AJ (ed): Neurosurgical perspectives on trigeminal neuralgia. Philadelphia, WB Saunders, 1977, pp 5362.

18. BROWN JA, PREUL M: Percutaneous trigeminal ganglion compression for trigeminal neuralgia. Experience in 22 patients and review of the literature. J Neurosurg 70:900-4, 1989.

19. BROWN JA, PREUL MC: Trigeminal depressor response during percutaneous microcompression to the trigeminal neuralgia. Neurosurgery 23:745-8, 1988.

20. BROWN JA, HOEFLINGER B, LONG PB, GUNNING WT, RHOADES R, BENNETT-CLARKE CA, CHIAIA NL, WEAVER MT: Axon and ganglion cell injury in rabbits after percutaneous trigeminal balloon compression. Neurosurgery 38:993-1004, 1996.

21. BURCHIEL KJ: Abnormal impulse geration in focally demyelinated trigeminal roots. J Neurosurg 53:67483, 1980.

22. BUSCAINO GVA: Fisiologia della nevralgia essenziale del trigemino. Acta Neurol (Napoli) 35:137-44, 1980.

23. BUTTI G, GAETANI P, GIORDANO MT, PAOLETTI P: Meningiomas of Menckel's cave. Surg Neurol 20:3059, 1983.

24. CORREA CF, TEIXEIRA MJ: Balloon compression of the Gasserian ganglion for the treatment of trigeminal neuralgia. Stereotact Funct Neurosurg 71:83-9, 1998a.

25. CORRÊA CF, TEIXEIRA MJ: Compressão do gânglio de Gasser com balão para o tratamento da nevralgia trigeminal. In Temas de Atualização em Neurocirurgia. Sociedade Brasileira de Neurocirurgia. Collectanea Symposium. Série Medicina e Saúde. Rio de Janeiro, Frontis \& Editorial, 1998b, pp 43-50.

26. CUSHING H: Major trigeminal neuralgias and their surgical treatment based on experiences with 332 gasserian operations; varieties of facial neuralgia. Am J Sci 160:157-64, 1920.

27. DALLESSIO DJ: Medical treatment of trigeminal neuralgia. Clin Neurosurg 24:579-83, 1976.

28. DALY BF, SAJOR EE: Inherited tic doloureux. Neurology (Minneap) 23:93-9, 1973.

29. DANA CL: Natural history of tic doloureux with remarks on treatment. JAMA 34:1100-3, 1900.

30. DANDY WE: Concerning cause of trigeminal neuralgia. Am J Surg 24:445-7, 1934.

31. DANDY WE: The treatment of trigeminal neuralgia by the cerebellar route. Ann Surg 96:787-95, 1932.

32. DELLOW PG, MORGAN MJ: Trigeminal nerve inputs and central blood pressure change in the cat. Arch Oral Biol 14:295-300, 1969.

33. DOMINGUEZ J, LOBATO RD, RIVAS J, GARGALLO MC, CASTELLS V, GOZALO A, SARABIA R: Changes in systemic blood pressure and cardiac rhythm induced 
by therapeutic compression of the trigeminal ganglion. Neurosurgery 34:422-8, 1994.

34. ESPOSITO S, DELITALA A, BRUNI P, HERNANDEZ $R$, CALLOVINI GM: Therapeutic protocol in the treatment of trigeminal neuralgia. Appl Neurophysiol 48(1-6):271-3,1985.

35. FIUME D, SCARDA G, NATALI G, DELLA VALLE G: La microcompressione percutanea del ganglio de Gasser. Una nuova terapia per le nevralgie del trigemio. Riv Neurol 55:387-91, 1985.

36. FRAIOLI B, ESPOSITO V, GUIDETTI B, CRUCCU G, MANFREDI M: Treatment of trigeminal neuralgia by thermocoagulation, glycerolization, and percutaneous compression of the Gasserian ganglion and/ or retrogasserian rootlets: long term results and therapeutic protocol. Neurosurgery 24:239-45, 1989.

37. FRAIOLI B, FERRANTE L, SANTORO A, DI GIUGENO $G$ : Recent progress in the treatment of trigeminal neuralgia: glycerol into the trigeminal cistern and percutaneous Gasserian compression by means of Fogarty's catheter. Acta Neurochir (Wien) 33:507-10, 1984.

38. FRAZIER CH: Bilateral trigeminal neuralgia. Ann Surg 100:770, 1934

39. FRAZIER CH, RUSSEL EC: Neuralgia of the face. Arch Neurol Psychiatry 11:557-63, 1924.

40. GARDNER WJ: Concerning the mechanism of trigeminal neuralgia and hemifacial spasm. J Neurosurg 19:947-58, 1962.

41. GARDNER WJ: Trigeminal neuralgia. Clin Neurosurg 15:1-56, 1968.

42. GERBER AM, MULLAN SF: Trigeminal nerve compression for neuralgia. In Gildenberg LP, Tasker RR (ed): Textbook of stereotactic and functional neurosurgery. New York, McGraw-Hill, 1998, pp 170713.

43. GOOR C, ONGERBOER de VISSER BW: Jaw and blink reflexes in trigeminal nerve lesions. An electrodiagnostic study. Neurology (Minneap) 26:95-7, 1976.

44. GREEN JD, de GROOT J, SUTIN J: Trigemino-bulbar reflex pathways. Am J Physiol 189:384-8, 1957.

45. HAKANSON S: Transoval trigeminal cisternography. Surg Neurol 10:137-43, 1978.

46. HARRIS W: An analysis of 1433 cases of paroxysmal trigeminal neuralgia (trigeminal-tic) and the results of Gasserian alcohol injection. Brain 63:209-24, 1940.

47. HARRIS W: Bilateral tic. Its association with heredity and disseminated sclerosis. Ann Surg 103:161-72, 1936.

48. HARTEL F: Ueber die intracranielle injektionsbehandlung der trigeminusneuralgie. Med Klin 10:5824, 1914.

49. HENDERSON WR: Trigeminal neuralgia: the pain and its treatment. Brit Med J 1:7-15, 1967.

50. HERZBERG L: Familial trigeminal neuralgia. Arch Neurol 37:285-6, 1980.

51. HOROWITHZ SH: Isolated facial numbers. Clinical significance and relation to trigeminal neuropathy. Ann Intern Med 80:49-53, 1974.

52. HUTCHINS LG, HARNSBERGER HR, HARDIN CW, DILLON WP, SMOKER WR, OSBORN AG: The radiologic assessment of trigeminal neuropathy. Am J Roentgenol 153:1275-82, 1989.

53. JANNETTA PJ: Arterial compression of the trigeminal nerve at the pons in patients with trigeminal neuralgia. J Neurosurg 26 (Suppl.):159-62, 1967a.

54. JANNETTA PJ: Microsurgical approach to the trigeminal nerve for tic doloureux. Prog Neurol Surg $7: 180-200,1976$
55. JANNETTA PJ: Vascular decompression in trigeminal neuralgia. In Samii M e Jannetta PJ (ed): The cranial nerves. Berlin, Spriger-Verlag, 1981, pp 331-40.

56. JANNETTA PJ, ROBBINS LJ: Trigeminal neuropathy. New observations. Neurosurgery 7:347-51, 1980.

57. JHO HD, LUNSFORD LD: Percutaneous retrogasserian glycerol rhizotomy. Current technique and results. Neurosurg Clin N Am 8:63-74, 1997.

58. KEHLER CH, BRODSKY JB, SAMUELS SI, BRITT RH, SILVERBERG GD: Blood pressure response during percutaneous rhizotomy for trigeminal neuralgia. Neurosurgery 10:200-2, 1982.

59. KILLIAN JM, FROMM GH: Carbamazepine in the treatment of neuralgia. Use and side effects. Arch Neurol 19:129-36, 1968.

60. KIMURA J: Eletrodiagnostic of trigeminal nerve. Orbicularis oculi reflex and masseter reflex in trigeminal neuralgia, paratrigeminal syndrome and other lesions of the trigeminal nerve. Neurology (Minneap) 20:574-83, 1970.

61. KNUDSEN V, KOLZE V: Neurinome of the Gasserian ganglion and the trigeminal root. Report of four cases. Acta Neurochir (Wien) 26:159-64,1972.

62. KUMADA M, DAMPNEY RAL, REIS DJ: The trigeminal depressor response: a novel vasodepressor response originating from the trigeminal system. Brain Res 119:305-26, 1977

63. LEVINTHAL R, BENTSON JR: Detection of small trigeminal neurinomas. J Neurosurg 45: 568-75,1976.

64. LEWY FH, GRANT FC: Physiopathologic and pathognomonic aspects of major trigeminal neuralgia. Arch Neurol Psychiat (Chicago) 40:1126-34, 1938.

65. LICHTOR T, MULLAN JF: A 10-year follow-up of percutaneous microcompression of the trigeminal ganglion. J Neurosurg 72:49, 1990.

66. LOBATO RD, RIVAS JJ, SARABIA M, LAMAS E: Percutaneous microcompression of the Gasserian ganglion for trigeminal neuralgia. J Neurosurg 72:546, 1990

67. MEGLIO M, CIONI B: Percutaneous procedures for trigeminal neuralgia: microcompression versus radiofrequency thermocoagulation. Personal experience 1. Pain 38:9-16, 1989.

68. MEGLIO M, CIONI B, d'ANNUNZIO V: Percutaneous microcompression of the Gasserian ganglion: personal experience. Acta Neurochir (Wien) 39:1423, 1987.

69. MENÉTREY D, BASBAUM A: Spinal and trigeminal projections to the nucleus of the solitary tract: a possible substrate for somatovisceral and viscerovisceral reflex activation. J Comp Neurol 255:43950, 1987.

70. MOSES HL: Comparative fine structure on the trigeminal ganglia including human autopsy studies. J Neurosurg 26:112-26, 1967.

71. MOTTA P, SOUZA MTK, SENGUPTA RP: Radiofrequência - termocoagulação no tratamento da neuralgia do trigêmeo. Análise de 100 casos. Arq Neuropsiquiatr (São Paulo) 38:33-44, 1980.

72. MULLAN S: Percutaneous microcompression of the trigeminal ganglion. In Rovit RL, Murali R, Jannetta PJ (ed): Trigeminal neuralgia. Baltimore, Willians \& Wilkins, 1990, pp 137-44.

73. MULLAN S, LICHTOR T: Percutaneous microcompression of the trigeminal ganglion for trigeminal neuralgia. J Neurosurg 59:1007-12, 1983.

74. NAIDICH TP, LIN JP, LEEDS NE, KRICHEFF II, GEORGE AE, CLASE NE, PUDLOWSKI RM, PASSALAQUA A: Computed tomography in the diagnosis 
of extra-axial posterior fossa masses. Radiology 120:333-9, 1976.

75. NUGENT GR, BERRY B: Trigeminal neuralgia treated by differential percutaneous radiofrequency coagulation of the Gasserian ganglion. J Neurosurg 40:51723, 1974

76. ONGERBOER de VISSER BW, GOOR C: Eletromyographic and reflex study in idiopathic and symptomatic trigeminal neuralgias, latency of the jaw and blink relfexes. J Neurol Neurosurg Psychiatry 37:1225-30, 1974.

77. ONGERBOER de VISSER BW, MELCHASE K, MENGENS PHA: Corneal reflex latency in trigeminal nerve lesions. Neurology (Minneap) 27:1164-7, 1977.

78. PALACIOS E, McGEE EE: The radiographic diagnosis of trigeminal neurinomas. J Neurosurg 36:153-6, 1972.

79. PENMAN J: The differential diagnosis and treatment of tic doloureux. Post Grad Med J 26:627-36, 1950.

80. PERAGUT JC, OLIVEIRA JG, FABRIZI A, SETHIAN $\mathrm{N}$ : Microcompression of Gasser's ganglion. A treatment of essential facial neuralgia. A propos of 70 cases. Neurochirurgie 37:111-4, 1991.

81. PERTUISET B, PHILIPPON J, MACHANAKIAN A: Électrothermie rétro-gasseriene dans la névralgie faciale. Ann Med Int (Paris) 126:657-60, 1975.

82. RAND RW: Gardner neurovascular decompression of the trigeminal and facial nerves for tic doloureux and hemifacial spasm. Surg Neurol 16:329-32, 1981.

83. RASMUSSEN P, RÜSHED J: Facial pain treated with carbamazepine (Tegretol). Acta Neurol Scand 46:38540, 1970

84. ROCKLIFF BW, DAVIS EW: Controlled sequential trial of carbamazepine in the trigeminal neuralgia. Arch Neurol 15:129-36, 1966.

85. RUGE D, BROCHNER R, DAVIS L: A study of the treatment of 637 patients with trigeminal neuralgia. J Neurosurg 15:528-36, 1958.

86. RUGGIERO DA, ROSS CA, REIS DJ: Projections from the spinal trigeminal nucleus to the entire length of the spinal cord in the rat. Brain Res 225:225-33, 1981.

87. RUSHTON JG, Mac DONALD HNA: Trigeminal neuralgia: special considerations of nonsurgical treatment. JAMA 165:437-40, 1957.

88. RUSHTON JG, OLAFSON RA: Trigeminal neuralgia associated with multiple sclerosis: report of 35 cases. Arch Neurol 13:383-6, 1965.

89. SAUNDERS RL: The role of the motor root in recurrence of trigeminal neuralgia. Headache,10:1447, 1971.

90. SCHIBUOLLA CT: Resultados imediatos do tratamento cirúrgico da nevralgia do glossofaríngeo. Dissertação de Mestrado, Universidade de São Paulo, 1982

91. SCHNEIDER RC: The syndrome of acute anterior spinal cord injury. J Neurosurg 12:95-122, 1955.

92. SEARLES RP, MLADINICH EK, MESSNER RP: Isolated trigeminal sensory neuropath: early manifestations of mixed connective tissue disease. Neurology 28:1286-9, 1978.

93. SHELDEN CH: Compression procedure for trigeminal neuralgia. J Neurosurg 25:374-81, 1966.

94. SIEGFRIED J: 500 percutaneous thermocoagulation of the Gasserian ganglion for trigeminal pain. Surg Neurol 8:126-31, 1977.

95. STÖHR M, PETRUCH F, SCHEGLMANN K: Somatosensory evoked potentials following trigeminal nerve stimulation in trigeminal neuralgia. Ann Neurol 9:636, 1981.
96. STOOKEY B, RANSOHOFF J: Trigeminal neuralgia. Its history and treatment. Springfield, Charles C. Thomas Publisher, 1959, pp 3-32.

97. SUGAYA E, MATSUO T, TAKAGI T: Direct current potential changes of the vagal nuclear area induced by trigeminal stimulation. Brain Res 369:369-72, 1986.

98. SWEET WH, POLETTI CE, MACON JB: Treatment of trigeminal neuralgia and other facial pains by retrogasserian injection of glycerol. Neurosurgery 9:647-53, 1981.

99. SWEET WH, POLETTI CE, ROBERTS JT: Dangerous rises in blood pressure upon heating of trigeminal rootlets: increased bleeding times in patients with trigeminal neuralgia. Neurosurgery 17:843-4, 1985.

100. TAARNHFJ P. Decompression of trigeminal root and posterior part of ganglion as treatment in trigeminal neuralgia. Preliminary communication. J Neurosurg 9:288-90, 1952.

101. TAHA JM, TEW Jr. J: Comparison of surgical treatment for trigeminal neuralgia: revaluation of radiofrequency rhizotomy. Neurosurgery 38:865-70, 1996.

102. TATOR $\mathrm{CH}, \mathrm{ROWED}$ DW: Fluoroscopy of foramen ovale as an aid to thermocoagulation of the Gasserian ganglion. Technical note. J Neurosurg 44:254-7, 1976.

103. TEIXEIRA MJ: A lesão do tracto de Lissauer e do corno posterior da medula espinal e a estimulação elétrica do sistema nervoso central para o tratamento da dor por desaferentação. Tese - Doutorado, Universidade de São Paulo, 1990.

104. TEIXEIRA MJ: A rizotomia percutânea por radiofreqüência e a descompressão vascular do nervo trigêmeo no tratamento das algias da face. Dissertação de Mestrado, Universidade de São Paulo, 1985.

105. TEIXEIRA MJ: Dor orofacial e ATM. Bases para o diagnóstico clínico. In Siqueira JTT, Lin TY (eds.): Dor. Princípios gerais de tratamento da dor. Curitiba, Editora Maio, 1999, pp 16-28.

106. TEIXEIRA MJ: Tratamento neurocirúrgico da dor neuropática. Rev Med 78:305-36, 1999 b.

107. TEIXEIRA MJ, NEVES ATA: Tratamento farmacológico da dor neuropática. Rev Med 78:222-75, 1999.

108. TEIXEIRA MJ, PIMENTA CAM, LIN TY, FIGUEIRÓ JAB: Assistência ao doente com dor. Rev Med 77:10510, 1998.

109. TERUI N, NUMAO Y, KUMADA M, REIS DJ: Identification of the primary afferent fiber group and adequate stimulus initiating the trigeminal depressor response. J Auton Nerv Syst 4:1-16, 1981.

110. THUREL R: Névralgie trijumeau et spasm faciale périphérique. Rev Neurol (Paris) 104:534-5, 1961.

111. URCULO E: MARTINEZ L: ARRAZOLA M, RAMIREZ $R$ : Macroscopic effects of percutaneous trigeminal ganglion compression (Mullan's technique): an anatomic study. Neurosurgery 36:776-9, 1995.

112. WHISLER WW, HILL BJ: A simplified technique for the injection of the gasserian ganglion using the fluoroscope for localization. Neurochirurgie 5:167, 1972.

113. WHITE JC, SWEET WH: Pain and the neurosurgeon. Springfield, Charles C Thomas Publisher, 1969.

114. YONAS $\mathrm{H}$, JANNETTA PJ: Neurinoma of the trigeminal root and atypical trigeminal neuralgia: their commonality. Neurosurgery 6:273-7, 1970. 
115. YOSHIMASU F, KURLAND LT, ELVELVACK LR: TiC doloureux in Rochester, Minnesota, 1945-1969. Neurology (Minneap) 22:952-6, 1972.

116. ZANUSSO M, CURRI D, LANDI A, COLOMBO F, VOLPIN L, CERVELLINNI P: Pressure monitoring inside Meckel' cave during percutaneous microcompression of gasserian ganglion. Stereotact Funct Neurosurg 56:37-43, 1991.
Original recebido em janeiro de 2002

Aceito para publicação em março de 2002

Endereço para correspondência:

Heider Lopes de Souza

Rua Agodi, 822 - ap. 601

CEP 59020-100 - Natal, RN

E-mail:heider@ufrnet.br 